\title{
Exploring systemic RNA interference in insects: a genome-wide survey for RNAi genes in Tribolium Yoshinori Tomoyasu** ${ }^{* \dagger}$, Sherry C Miller ${ }^{* \dagger}$, Shuichiro Tomita ${ }^{\ddagger}$, Michael Schoppmeier§, Daniela Grossmann" and Gregor Bucherף
}

\begin{abstract}
Addresses: *Division of Biology, Kansas State University, Manhattan, Kansas 66506, USA. ${ }^{\dagger}$ K-State Arthropod Genomics Center, Kansas State University, Manhattan, Kansas 66506, USA. "Insect Genome Research Unit, National Institute of Agrobiological Sciences, 1-2, Owashi, Tsukuba, Ibaraki 305-8634, Japan. §Universitat Erlangen, Institut fur Biologie, Abteilung fur Entwicklungsbiologie, Staudtstr., D-91058 Erlangen, Germany. "Johann-Friedrich-Blumenbach-Institut für Zoologie und Anthropologie, Georg-August-Universität Göttingen, Abteilung Entwicklungsbiologie, Justus-von-Liebig-Weg, 37077 Göttingen, Germany.
\end{abstract}

Correspondence: Yoshinori Tomoyasu. Email: tomoyasu@ksu.edu

Published: 17 January 2008

Genome Biology 2008, 9:RI0 (doi:10.1 I86/gb-2008-9-I-r10)

The electronic version of this article is the complete one and can be found online at http://genomebiology.com/2008/9/I/RI0
Received: 20 July 2007

Revised: 13 November 2007

Accepted: 17 January 2008

(c) 2008 Tomoyasu et al.; licensee BioMed Central Ltd.

This is an open access article distributed under the terms of the Creative Commons Attribution License (http://creativecommons.org/licenses/by/2.0), which permits unrestricted use, distribution, and reproduction in any medium, provided the original work is properly cited.

\begin{abstract}
Background: RNA interference (RNAi) is a highly conserved cellular mechanism. In some organisms, such as Caenorhabditis elegans, the RNAi response can be transmitted systemically. Some insects also exhibit a systemic RNAi response. However, Drosophila, the leading insect model organism, does not show a robust systemic RNAi response, necessitating another model system to study the molecular mechanism of systemic RNAi in insects.

Results: We used Tribolium, which exhibits robust systemic RNAi, as an alternative model system. We have identified the core RNAi genes, as well as genes potentially involved in systemic RNAi, from the Tribolium genome. Both phylogenetic and functional analyses suggest that Tribolium has a somewhat larger inventory of core component genes than Drosophila, perhaps allowing a more sensitive response to double-stranded RNA (dsRNA). We also identified three Tribolium homologs of $C$. elegans sid-I, which encodes a possible dsRNA channel. However, detailed sequence analysis has revealed that these Tribolium homologs share more identity with another $C$. elegans gene, tag130. We analyzed tag- 130 mutants, and found that this gene does not have a function in systemic RNAi in C. elegans. Likewise, the Tribolium sid-like genes do not seem to be required for systemic RNAi. These results suggest that insect sid- $I$-like genes have a different function than dsRNA uptake. Moreover, Tribolium lacks homologs of several genes important for RNAi in C. elegans.

Conclusion: Although both Tribolium and C. elegans show a robust systemic RNAi response, our genome-wide survey reveals significant differences between the RNAi mechanisms of these organisms. Thus, insects may use an alternative mechanism for the systemic RNAi response. Understanding this process would assist with rendering other insects amenable to systemic RNAi, and may influence pest control approaches.
\end{abstract}




\section{Background}

A decade has passed since the discovery that double-stranded RNA molecules (dsRNA) can trigger silencing of homologous genes, and it is now clear that RNA-mediated gene silencing is a widely conserved cellular mechanism in eukaryotic organisms [1-3]. RNA-mediated gene silencing can be categorized into two partially overlapping pathways; the RNA interference (RNAi) pathway and the micro-RNA (miRNA) pathway [2,4-6]. RNAi is triggered by either endogenous or exogenous dsRNA, and silences endogenous genes carrying homologous sequences at both the transcriptional and posttranscriptional levels. In contrast, the miRNA pathway is triggered by mRNAs transcribed from a class of non-coding genes. These mRNAs form hairpin-like structures, creating double-stranded regions in a molecule (pre-miRNA). In either pathway, dsRNA molecules are processed by Dicer RNase III proteins into small RNAs (for a review of Dicer, see [7]), which are then loaded into silencing complexes (reviewed in [8]). In the RNAi pathway, small RNAs are called short interfering RNAs (siRNAs) and are loaded into RNAinduced silencing complexes (RISC) for post-transcriptional silencing, or RNA-induced initiation of transcriptional gene silencing (RITS) complexes for transcriptional silencing. In contrast, miRNAs (small RNAs in the miRNA pathway) are loaded into miRNA ribonucleoparticles (miRNPs) (see [2] for a review of silencing complexes). dsRNA binding motif (dsRBM) proteins, such as R2D2 and Loquacious, help small RNAs to be loaded properly into silencing complexes [9-14]. Using the small RNA as a guide, silencing complexes find target mRNAs and cleave them (in the case of RISC) or block their translation (in the case of miRNP). RITS is involved in transcriptional silencing by inducing histone modifications. Argonaute family proteins are the main components of silencing complexes, mediating target recognition and silencing (reviewed in $[15,16]$ ). The RNAi pathway and miRNA pathway are essentially parallel, using related but distinct proteins at each step. For instance, in Drosophila, Dicer2, R2D2 and Argonaute2 are involved in the RNAi pathway, while Dicer1, Loquacious, and Argonaute1 function in the miRNA pathway $[10,12,14,17,18]$. In Caenorhabditis elegans, the primary siRNAs processed by Dicer are used as guides for RNA-dependent RNA polymerase (RdRP) to produce secondary dsRNAs in a two-step mechanism $[19,20]$. This amplification step is apparently essential for the RNAi effect in C. elegans [19-21].

RNAi has become a widely used tool to knock down and analyze the function of genes, especially in non-model organisms where the systematic recovery of mutants is not feasible. However, in some organisms, delivery of dsRNA presents a problem. Injecting dsRNA directly into eggs seems to be the most efficient way to induce an RNAi effect; however, many embryos do not survive the injection procedure, the number of knock-down embryos generated is limited and all individuals have been injured by the injection. In addition, in some species such as Drosophila, dsRNA injection into embryos sometimes results in a mosaic pattern of knock-down effect
[22]. Furthermore, knocking down genes frequently kills the embryo, making it difficult to perform functional analyses of these genes at later, post-embryonic stages. In a few highly established model systems, such as Drosophila, hairpin constructs can be used to overexpress dsRNA in particular tissues at certain stages [23-25]. Virus-mediated methods offer an alternative way to overexpress dsRNA [26]; however, some organisms seem to eliminate virus quickly (M Jindra, personal communication), making it difficult to apply this method globally. In some organisms (but not others) dsRNA can be introduced at postembryonic stages by feeding, soaking or direct injection (for example, larval/nymphal stage [2731], adult stage [32-37], feeding RNAi [38,39], soaking RNAi [40]). The dsRNA somehow enters cells and induces an RNAi effect systemically. Transmission of the RNAi effect to the next generation is also possible (parental RNAi [41-45]). However, some organisms, such as the silkworm moth Bombyx mori, do not show a robust systemic RNAi response [46] (ST, unpublished data; R Futahashi and T Kusakabe, personal communications; but see also [47-49] for some successful cases). Understanding the molecular mechanisms underlying systemic RNAi may help in applying RNAi techniques to these organisms.

Systemic RNAi was first described in plants as spread of posttranscriptional gene silencing [50-52]. The first animal in which RNAi was shown to work systemically was C. elegans, where it has been thoroughly investigated $[1,53]$ (for reviews of systemic RNAi, see [54-57]). The phenomenon can be subdivided into two distinct steps: uptake of dsRNA by cells, and systemic spreading of the RNAi effect [58]. Several genes have been identified in $C$. elegans as important for systemic spread but not for the interference itself. sid-1 encodes a multi-transmembrane domain protein, which is thought to act as a channel for dsRNA [53,59]. Mosaic analysis in C. elegans as well as the overexpression of Sid-1 in cultured cells show that Sid-1 is involved in the dsRNA uptake step in both somatic and germ-line cells [53,59]. Three more proteins, Rsd-2, Rsd-3, and Rsd-6, have been identified as important factors for the systemic RNAi response in germ-line but not somatic cells [6o]. Recently, over 20 genes have been reported to be necessary for dsRNA uptake in Drosophila tissue culture cells $[61,62]$. Many of the genes identified in this system have been previously implicated in endocytosis, suggesting that this process may play an important role in dsRNA uptake also in other cells $[61,62]$.

Interestingly, core RNA machineries are not involved in systemic RNAi spreading in C. elegans. Homozygous Argonaute mutant (rde-1) individuals are still capable of transmitting the RNAi effect from intestine to gonad [63]. The same result is observed in $r d e-4$ mutants ( $r d e-4$ encodes a dsRBM protein that acts upstream of Rde-1) [63]. These mutants produce only initial siRNAs, which represent only a trace amount compared to the secondary siRNAs and are not sufficient to trigger any RNAi response [21,64]. These data indicate that, 
at least in these mutant conditions, siRNA production and amplification are not necessary for spreading of the RNAi effect in C. elegans, suggesting that dsRNA itself may be the transmitting factor for RNAi spreading. Longer dsRNA is preferably imported by tissue culture cells overexpressing the C. elegans sid-1 gene, which supports this view [59]. Moreover, 50 bp dsRNA injected into an intestinal cell is too short to induce systemic RNAi in C. elegans [59], suggesting that it is not siRNAs or dsRNA subsequently produced by RdRP, but rather the long initial dsRNA, which is critical for the systemic RNAi response.

Although, systemic RNAi spreading from cell to cell has not been shown in any animals other than C. elegans (spreading does not seem to occur in Drosophila ([65]), systemic uptake of dsRNA by cells seems to be conserved in some insects [2730,32-37,41,42,45]. Unfortunately, the systemic aspect of RNAi in Drosophila, the prime insect model organism, has not been studied thoroughly, and the extent to which systemic RNAi occurs in this insect is still unknown. Some tissues in Drosophila adults (including oocytes) [35,36,45] seem to be capable of taking up dsRNA; however, the systemic RNAi response seems to be greatly reduced in the larval stage (SCM and YT, unpublished data). In addition, parental RNAi at the pupal stage for some genes has failed (GB and M Klingler, unpublished data). The lack of a robust systemic RNAi response in Drosophila necessitates another model system if systemic RNAi is to be studied in insects. The red flour beetle, Tribolium castaneum, is the best characterized insect genetic model system besides Drosophila. Since Tribolium has the ability to respond to dsRNA systemically [27,41], it is an ideal model system for studying this process in insects.

The recently completed genomic sequence of $T$. castaneum [66] allowed us to comprehensively analyze the inventory of Tribolium homologs of genes involved in RNA-mediated gene silencing and the systemic RNAi response. Our results suggest that the molecular mechanisms for both RNAi amplification and dsRNA uptake in Tribolium are different from those in C. elegans. Therefore, systemic RNAi in insects might be based on a different mechanism that remains to be discovered. We also noticed several differences in the number of RNAi core component genes between Tribolium and Drosophila. These differences might contribute to the robust RNAi response in Tribolium. Based on our results we discuss several factors that might make Tribolium so amenable to systemic RNAi.

\section{Results \\ Core RNAi components}

Although the core components of RNA-mediated gene silencing are usually well conserved among species, the number and the degree of conservation of these proteins often vary between species. The efficiency of RNAi might affect the degree of systemic RNAi response. Therefore, we have surveyed genes that encode some core RNAi components.

\section{Dicer and dsRBM protein family}

Dicer family proteins are involved in the production of small RNA molecules and have several conserved motifs (Figure 1c) [7,67]: two amino-terminal DExH-Box helicase domains, a PAZ (Piwi/Argonaute/Zwille) domain, tandem RNase III domains and a carboxy-terminal dsRNA binding domain. A single Dicer protein is involved in both the siRNA and miRNA pathways in C. elegans [67-69]. In contrast, different Dicer proteins are assigned to the siRNA and miRNA pathways in Drosophila [17]. Dcr-1, which retains a PAZ domain but lacks an amino-terminal helicase domain (Figure 1c), is involved in the miRNA pathway [17]. On the other hand, Dcr-2 seems to lack a full-length PAZ domain but has the helicase domain (Figure 1c), and is involved in the RNAi pathway [17]. In addition, a distantly related RNase III emzyme, Drosha, is involved in the maturation of miRNA precursors [70,71].

We identified one drosha and two Dicer genes in the Tribolium genome. One gene (Tc-Dcr-1) clearly codes for the ortholog of Dm-Dcr-1 and Ce-Dcr-1. The sequence of the second Tribolium Dicer does not clearly cluster with Dm-Dcr-2 (Figure 1a, b). However, as it shares some similarities in domain architecture with Dm-Dcr-2 (Figure 1c, and see below), we tentatively call it Tc-Dcr-2.

A ScanProsite search [72] has revealed that, in contrast to Dm-Dcr-1, which lacks a helicase domain, Tc-Dcr-1 retains both the helicase and PAZ domains (Figure 1c). This domain architecture makes Tc-Dcr-1 more similar to Ce-Dcr-1. TcDcr-2 also has both domains, but the PAZ domain is more diverged (Figure 1c). ScanProsite shows high scores for the PAZ domains of Ce-Dicer-1, Tc-Dcr-1, and Dm-Dcr-1 (scores of 24, 23 and 30, respectively), while the PAZ domain in TcDcr-2 shows a lower score (score 17) (see Materials and methods for a brief explanation of these scores). Dm-Dcr-2, which lacks a full-length PAZ domain, shows a much lower score for the PAZ domain region (score 8). Tc-Dcr-2 also lacks the carboxy-terminal dsRNA binding domain. The diverged PAZ domain and the lack of the dsRNA binding domain make TcDcr-2 more similar to Dm-Dcr-2 (Figure 1c).

A group of dsRBM-containing proteins act with Dicer to load small RNA molecules into a silencing complex. In Drosophila, each Dicer protein acts with a particular dsRBM protein: Loquacious (Loqs) for Dcr-1, R2D2 for Dcr-2, and Pasha for Drosha [10-14,73]. Interestingly, these proteins seem to determine the specificity of Dicer proteins, since Drosophila Dcr-1, which normally processes miRNAs, can instead produce siRNA in a loqs mutant $[11,14]$. This suggests that differences in these dsRBM-containing proteins might affect the efficiency of RNAi in different organisms. 
(a)

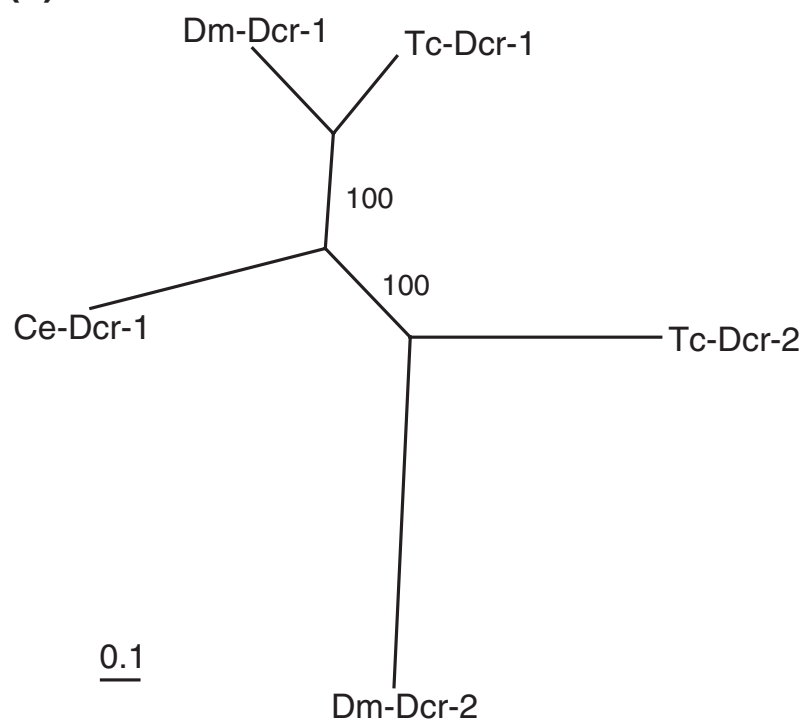

(b)

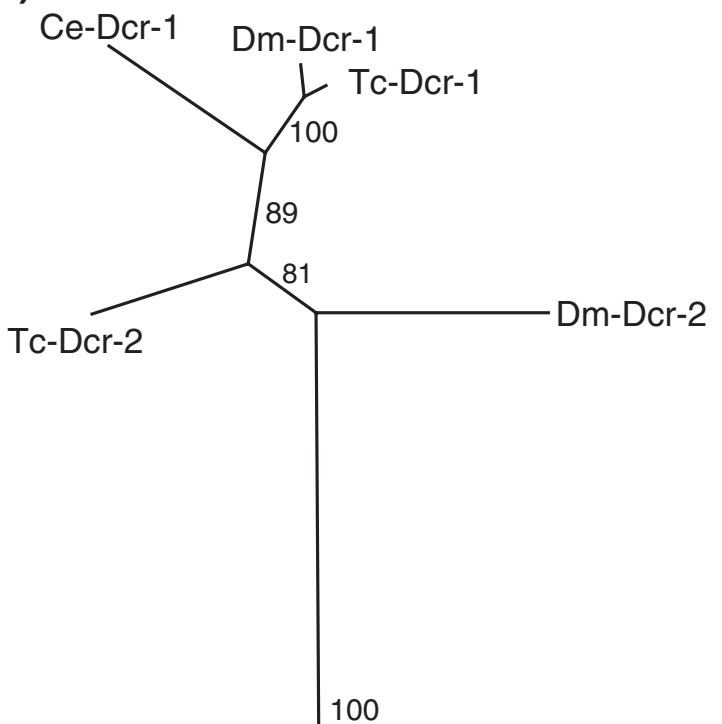

$\underline{0.1}$

(c)

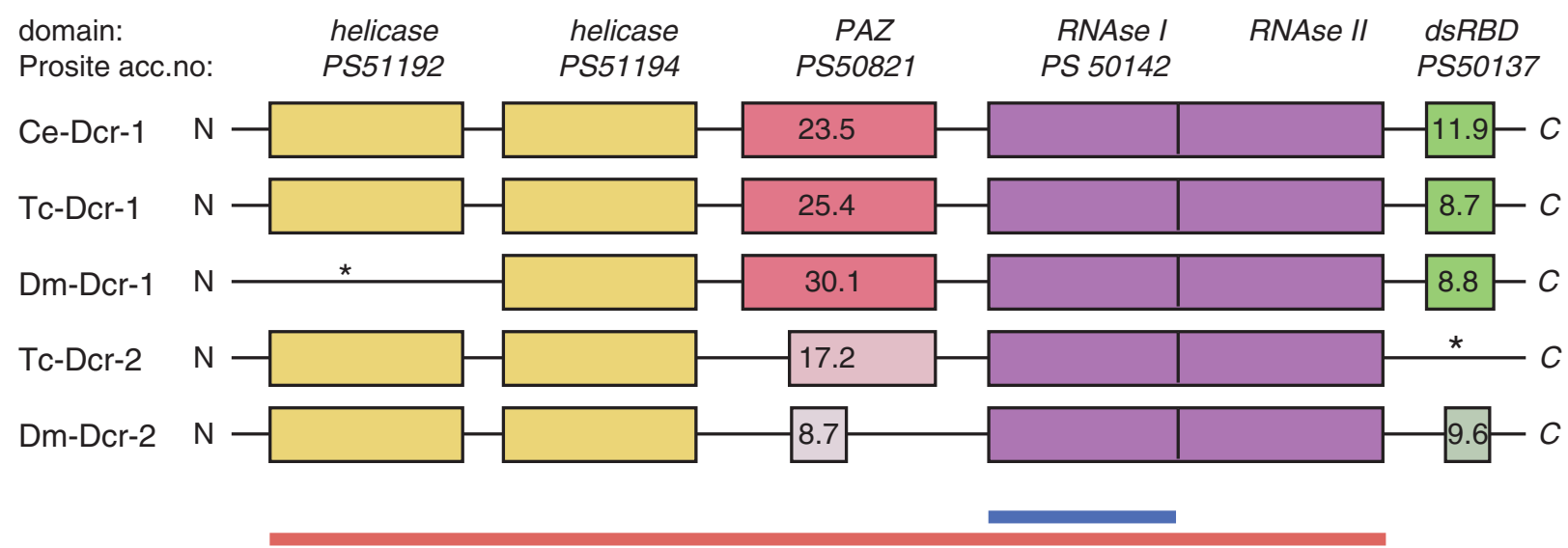

Figure I

Phylogenetic and protein domain analysis of Dicer proteins. (a, b) Phylogenetic analysis of Dicer proteins (a) and with Drosha as an outgroup (b). The tree in (a) was composed based on the alignments of full-length Dicer proteins without dsRBD (c, red underline), while the tree in (b) was based on the RNase I domain (c, blue underline). The Drosophila and Tribolium Dcr-I proteins cluster together, indicating clear orthology. In contrast, orthology of Dcr-2 proteins in these insects is less clear since they do not cluster together. (c) Domain architecture of Dicer proteins. Although our phylogenetic analysis cannot solve the orthology of insect Dcr-2 proteins, the similarity in the domain architectures of Dm-Dcr-2 and Tc-Dcr-2 suggests that they might be orthologous. Tc-Dcr-I has a similar domain architecture to Ce-Dcr-I, which is involved both in RNAi and miRNA pathways, suggesting that Tc-Dcr-I might also be involved in both pathways (unlike Dm-Dcr-I, which is involved only in the RNAi pathway). The ScanProsite scores are shown and the location of domain truncations is indicated. The first helicase domain in Dm-Dcr-I and dsRBD in Tc-Dcr-2 (indicated by an asterisk) are not recognized by ScanProsite but some conserved residues are identified by ClustalW alignment. 
We found clear orthologs of Drosophila loqs and pasha in Tribolium (Figure 2). In contrast, the Tribolium genome contains two R2D2-like genes (we named one of them Tc-R2D2 and the other $T c-C_{3} P O$ ), but orthology with Drosophila R2D2 is not as clear as for the other dsRBM proteins (Figure 2).

In conclusion, Drosophila and Tribolium have the same number of Dicer proteins. However, similarity of domain architecture of Tc-Dcr-1 to Ce-Dcr-1 (rather than to Dm-Dcr1) suggests that, in addition to Tc-Dcr-2, Tc-Dcr-1 could also be involved in both the miRNA and RNAi pathways, perhaps contributing to the robust RNAi response in Tribolium. The presence of an additional R2D2-like protein might also help make Tribolium hypersensitive to dsRNA molecules taken up by cells.

\section{Argonaute family}

Argonaute proteins are core components of RISC and miRNP, and are involved in siRNA-based as well as miRNA-based silencing $[2,16]$. Some Argonaute proteins are also involved in transcriptional silencing as a component of RITS [74,75]. Different Argonaute proteins are used for each process [16]. For instance, in Drosophila, Ago-1 and Ago-2 are predominantly used for miRNA and siRNA pathways, respectively [18], while Piwi, Aubergine (Aub), and Ago-3 are used for transcriptional silencing [76-79]. Argonaute proteins contain two distinctive domains: a PAZ domain and a PIWI domain [16]. The PAZ

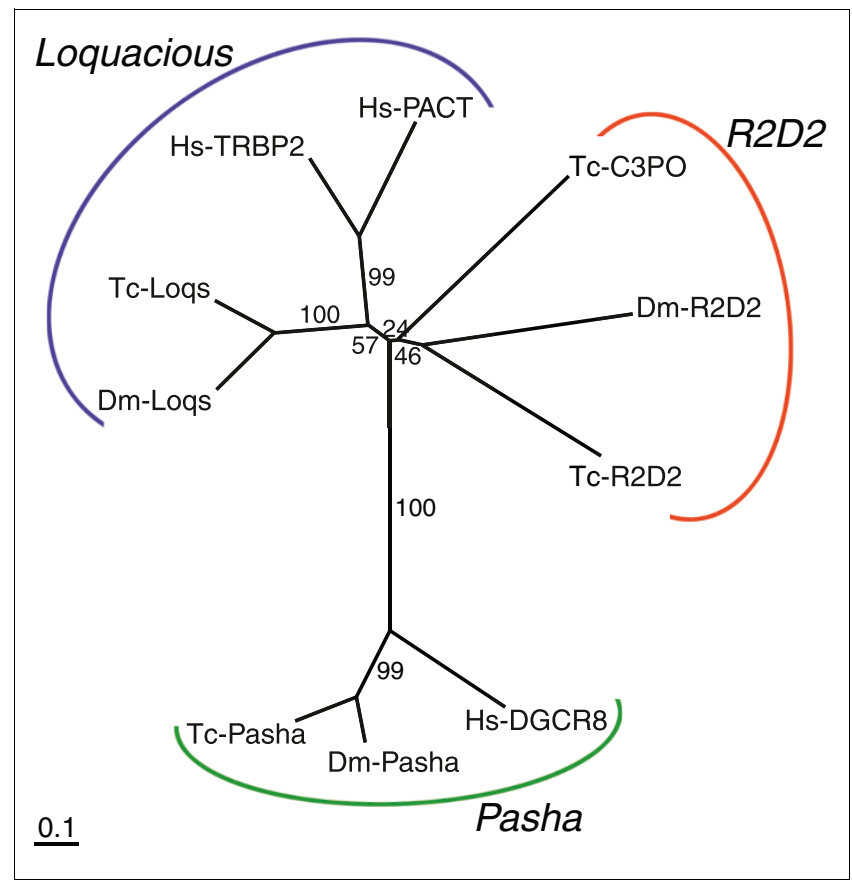

\section{Figure 2}

Phylogenetic analysis of dsRBM proteins. The neighbor-joining tree is based on alignment of the tandem dsRBM domains. The Tribolium genome contains two R2D2-like proteins (Tc-R2D2 and Tc-C3PO) while Drosophila has only one. PACT [135], TRBP2 [136,137], and DGCR8 [138] were included as human counterparts. domain seems to be involved in dsRNA binding, while the PIWI domain possesses RNase activity.

There is a striking expansion of Argonaute proteins in C. elegans (27 Argonaute proteins have been identified) [80]. As in Drosophila, these Argonaute proteins function in different processes. Rde-1 and Ergo-1 have been identified to act in the RNAi pathway [9,80], while Alg-1 and Alg-2 are important for the miRNA pathway [81]. Yigit et al. [80] identified yet another class of Argonaute proteins, the secondary Argonautes (Sago), that interact specifically with the siRNAs produced via RdRP amplification but not with the initial siRNAs. These results led the authors to propose a two-step model: first, the primary siRNAs, which are produced from the initial dsRNA, bind specifically to the initial Argonautes (Rde-1 or Ergo-1), and second, subsequent amplification by RdRP leads to the production of secondary siRNAs, which exclusively bind to secondary Argonaute proteins. This two-step recognition is proposed to be required for amplification of the RNAi effect, and at the same time possibly reducing off-target effects. As the secondary Argonaute proteins lack critical metal binding residues in the catalytic RNAse H-related PIWI domain, they are predicted to recruit other nucleases for degradation of target mRNAs [8o].

Both Tribolium and Drosophila have five Argonaute genes. To investigate the orthology relationships of these genes we calculated a tree based on an alignment of the PIWI domains of all Tribolium and Drosophila Argonaute proteins, a representative selection of $C$. elegans paralogs and the single Schizosaccharomyces pombe Argonaute protein (Figure 3; see Additional data file 1 for the alignment).

A single miRNA class Argonaute (Ago-1 in Drosophila and Alg-1/Alg-2 in C. elegans) is present in Tribolium (Tc-Ago-1). For the siRNA class Argonautes, we found two Ago-2 paralogs in Tribolium (Tc-Ago-2a and Tc-Ago-2b) that probably stem from a duplication in the lineage leading to beetles. These two proteins are clearly orthologous to Drosophila Ago-2; however, the relationships to C. elegans Rde-1 and Ergo-1 are not resolved in our analysis. The duplication of Ago-2 in Tribolium might lead to higher amounts of Tc-Ago2 protein and, hence, an enhanced RNAi response.

For the Piwi/Aub class Argonautes, which are involved in transcriptional silencing, we find one Tribolium ortholog (TcPiwi) of the Drosophila Piwi and Aub. One additional protein of this family (Tc-Ago3) is orthologous to a recently described Drosophila protein, Dm-Ago3 [77,82]. All these insect PIWItype proteins are orthologous to the C. elegans Prg-1 and Prg2.

Importantly, we do not find any homologs of secondary Argonaute proteins (represented by Ce-Ppw-1 and Ppw-2 in our tree) in either Tribolium or Drosophila (Figure 3). Furthermore, we confirmed that all Tribolium and Drosophila Argo- 


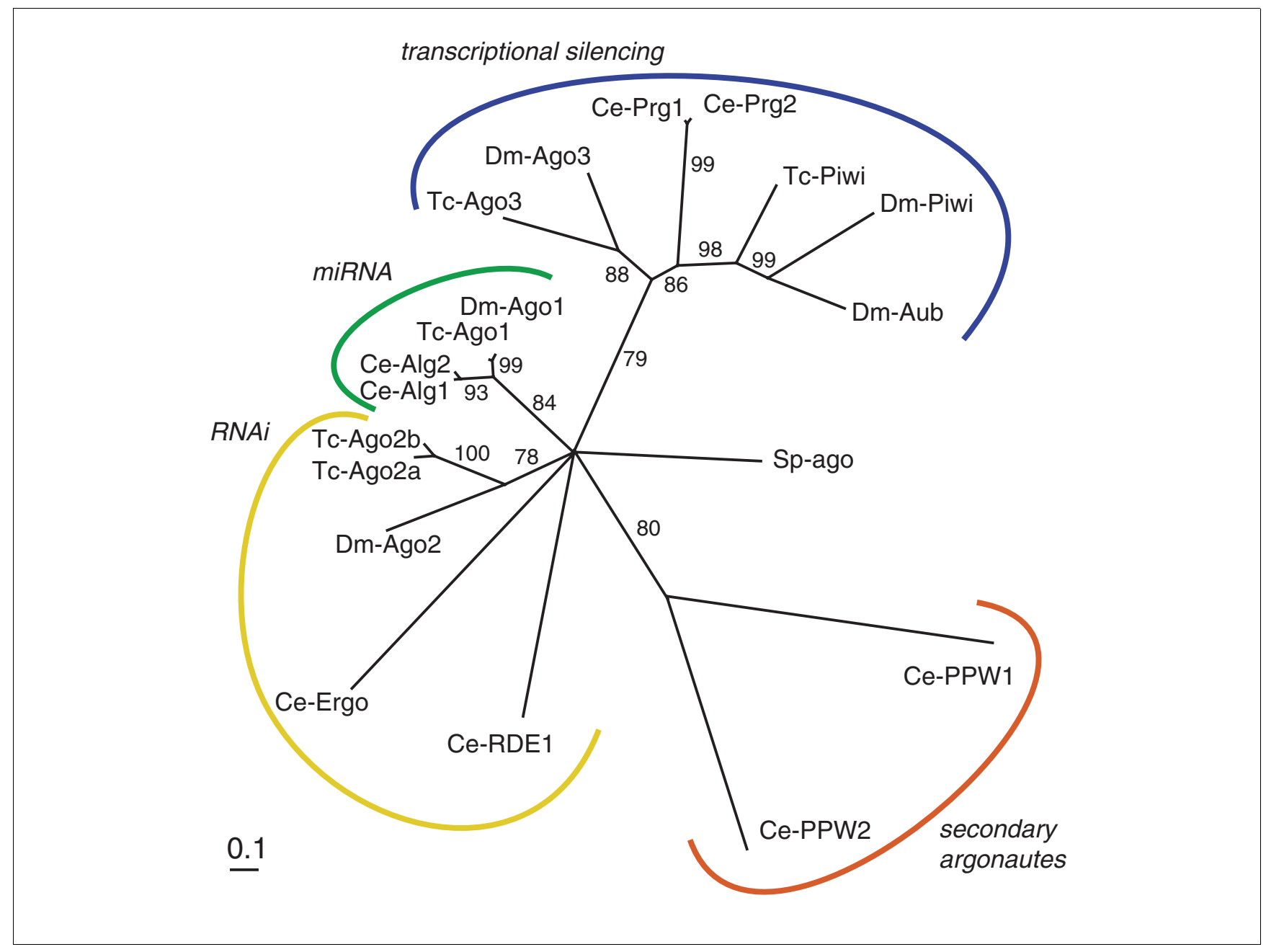

Figure 3

Phylogenetic analysis of Argonaute proteins. The neighbor-joining tree is based on the alignment of the conserved PIWI domain. Argonaute proteins can be categorized into four groups, each important for a different process; the RNAi pathway, the miRNA pathway, transcriptional silencing, and amplification of the RNAi effect (secondary Argonautes). Tribolium and Drosophila lack secondary Argonautes, suggesting that the secondary Argonaute-based amplification mechanism is not conserved in these insects.

naute proteins do have the metal binding residues of the PIWI domain, unlike the C. elegans secondary Argonaute proteins, which lack them [80]. The only exception is Drosophila Piwi, which has a lysine instead of a histidine in the third position. These data, along with the fact that the Tribolium genome lacks an ortholog of RdRP (see below), suggest that the twostep RNAi mechanism of RdRP-mediated amplification followed by secondary Argonaute function is not conserved in either Tribolium or Drosophila. The different abilities of Drosophila and Tribolium to perform systemic RNAi might, therefore, depend on factors other than the Argonaute repertoire in these insects.

\section{Absence of RNA-dependent RNA polymerase in Tribolium}

Systemic RNAi relies on the distribution of the trigger dsRNA, its uptake and subsequent efficient gene knockdown in cells. The distribution of the dsRNA trigger leads to its dilu- tion [83]. Hence, a mechanism for enhancing the signal may be required for efficient silencing. RdRP is a key for the amplification of the RNAi effect in C. elegans as well as in several plants $[19,20,84,85]$. It is possible that Tribolium has a similar amplification mechanism. However, we do not find a gene encoding an RdRP-related protein in the Tribolium genome by BLAST searches. Moreover, a BLAST search of all metazoan genes in the NCBI database identified RdRP genes only in several Caenorhabditis species and a cephalochordate Branchiostoma floridae [86]. Even some nematode species outside Caenorhabditis do not seem to carry RdRP genes. All other eukaryotic RdRPs belong to plants, fungi or protists, suggesting that RdRP is not conserved in animals (Figure 4). The lack of an RdRP gene in Tribolium suggests that the strong RNAi response in Tribolium does not rely on amplification of the trigger dsRNA by RdRP. 


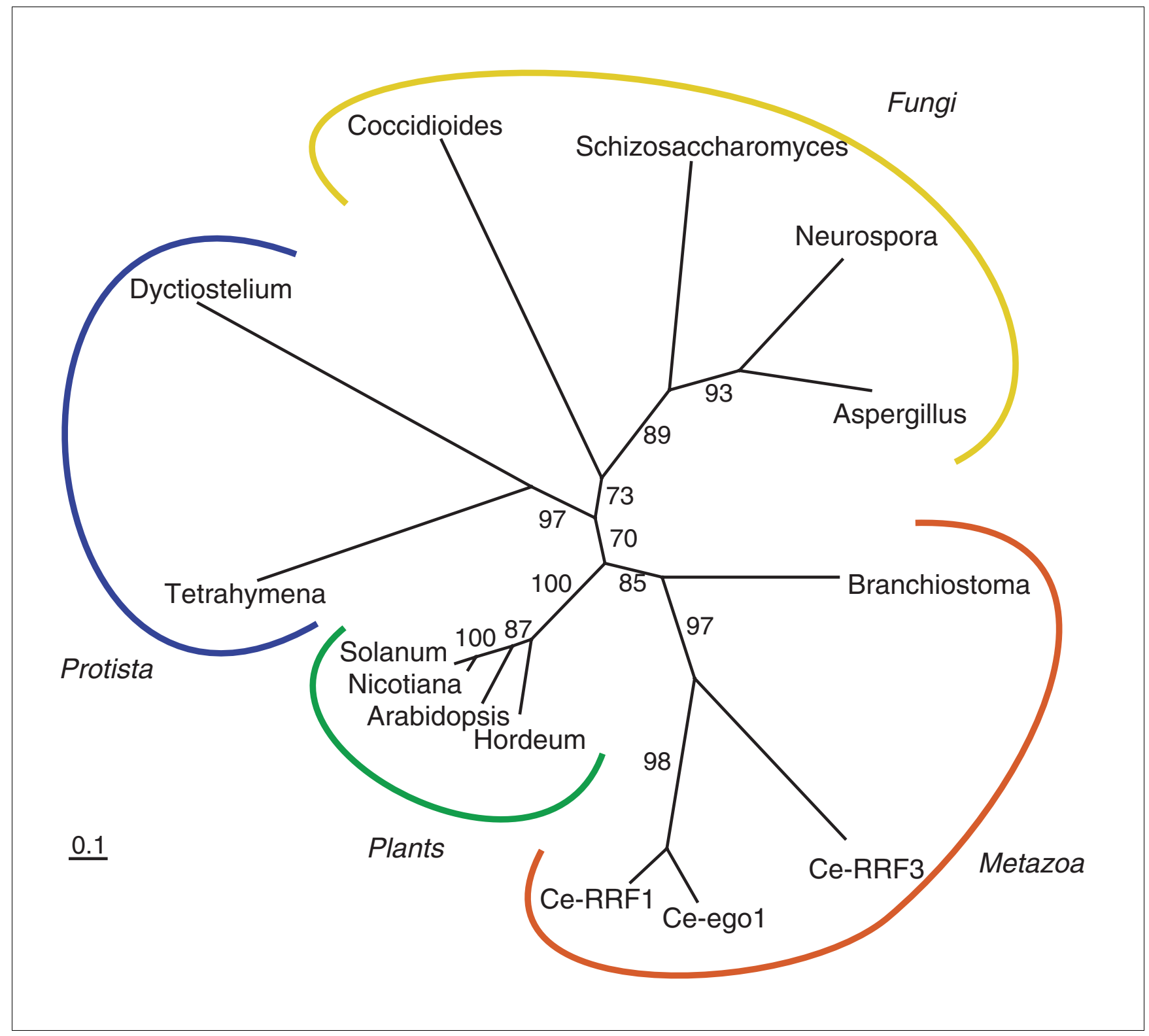

Figure 4

Distribution of RdRP in eukaryotes. Although RdRPs are present in many plants, fungi and protists (a selection is included in this tree), of the Metazoa, only Caenorhabditid nematodes and a chordate Branchiostoma are found to carry RdRP genes. Plant and protist RdRPs cluster together with very high support, while fungus and animal RdRPs comprise distinct clusters. Caenorhabditid RdRPs are represented by the three $C$. elegans paralogs RRF-I/3 and Ego-I.

Species names of the organisms shown in this tree are as follows: animals, Branchiostoma floridae; fungi, Coccidioides immitis, S. pombe, Neurospora crassa and Aspergillus terreus; plants, Hordeum vulgare, Arabidopsis thaliana, Nicotiana tabacum and Solanum lycopersicum; protists, Dictyostelium discoideum and Tetrahymena thermophila.

Eri-I-like exonuclease family

In C. elegans, several tissues, such as the nervous system, are refractory to RNAi, apparently due to the expression of eri-1 [87]. Abundant siRNA accumulates in eri-1 mutants, suggesting that Eri-1 is involved in siRNA degradation [87]. The eri1 gene encodes an evolutionarily conserved protein that contains a SAP/SAF-box domain and DEDDh family exonuclease domain [87]. The expression level and/or tissue specificity of eri-1 homologs might cause differences in sensitivity to dsRNA among organisms.

We have identified an eri-1-like gene in Tribolium. 5' and 3' rapid amplification of cDNA ends (RACE) analysis has revealed that this gene encodes a 232 amino acid protein (see Materials and methods for details). We also found a close homolog of this gene in Drosophila (CG6393, Dm-snipper). 


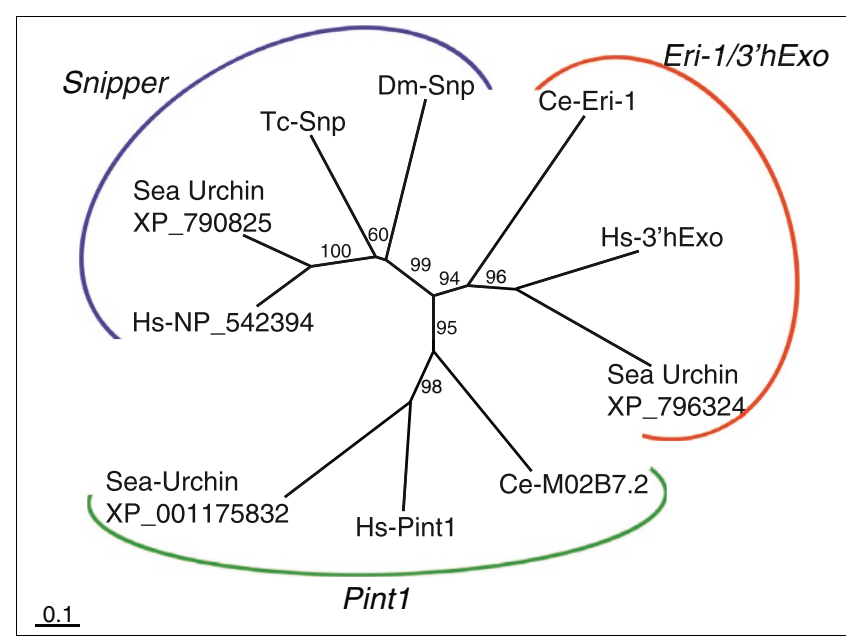

Figure 5

Phylogenetic analysis of Eri-I-like exonucleases. The neighbor-joining tree is based on the alignment of the exonuclease domain. Eri-I-like nucleases cluster into three subclasses: Eri-I/3'Exo, Snipper, and Pintl. Tribolium and Drosophila have only Snipper-type nucleases. One human and three sea urchin (Strongylocentrotus purpuratus) proteins are represented by NCBI accession numbers.

Interestingly, these genes are lacking the amino-terminal SAP/SAF-box domain. Also, phylogenetic analysis using the nuclease domain (Additional data file 1) reveals that the insect homologs cluster together, while Ce-Eri-1 and its human ortholog (3'hExo; three prime histone mRNA exonuclease [88]) compose another subclass. We subsequently noticed that there are at least three subclasses of nucleases closely related to Eri-1 in metazoans: the Eri-1/ 3'hExo subclass, the Pint1 (Prion Interactor 1 [89], also named Prion protein interacting protein (PrPIP) in [90]) subclass, and the Snipper subclass (Figure 5). Humans as well as sea urchins have all three subclasses of nucleases. C. elegans has at least two types of these nucleases, which belong to the Eri-1/3'hExo and Pint1 subclassses, respectively. In addition, it contains another nuclease (Cell-death-related nuclease 4 (Crn-4) [91]), whose position relative to the three subclasses of nucleases is unclear. Crn-4 clusters with C. elegans Eri-1 (Additional data file 2), but this affinity is questionable since Crn-4 does not share the amino-terminal region that is conserved in other members of the Eri-1/3'Exo subclass. The Tribolium and Drosophila nucleases, with their vertebrate and sea urchin orthologs, compose a distinct subclass (Snipper subclasss). This suggests that Drosophila and Tribolium lack nucleases belonging to the Eri-1 subclass, and that the insect nucleases might have a function other than siRNA digestion.

Recently, the Drosophila nuclease has been characterized as Snipper (Snp) [90]; therefore, we have named the Tribolium ortholog Tc-Snp. Although Snp can cleave RNA as well as DNA molecules in vitro, Snp seems to have no role in RNAi in Drosophila [90]. This supports our idea that the Snp subclass nucleases might not have an important role in the RNAi path- way. In conclusion, it is unlikely that nucleases related to Eri1 are causing the differential sensitivity to dsRNA in Tribolium and Drosophila.

\section{Candidate factors for systemic RNAi in Tribolium}

Several proteins are important for the systemic spread of the RNAi response in C. elegans but not for the RNAi pathway itself $[53,60]$. However, the degree of conservation of these proteins in other organisms has not been described. The presence of these factors might be critical for robust systemic RNAi. In addition, dozens of proteins have recently been identified as crucial for dsRNA uptake in Drosophila S2 cells $[61,62]$. We have screened the Tribolium genome for homologs of both of these groups of proteins.

\section{Sid-I-like proteins}

Sid-1 is the best characterized protein involved in systemic RNAi in C. elegans [53,59]. The Sid-1 protein contains a long amino-terminal extracellular domain followed by an array of transmembrane domains, which are inferred to form a channel for dsRNA molecules [53,59]. Mosaic analysis in C. elegans using a sid-1 overexpression construct showed that Sid1 is cell-autonomously required for receiving the systemic RNAi signal (it is still possible that Sid-1 is also involved in the RNAi spreading step) [53]. Overexpression of sid-1 in Drosophila culture cells also enhances the ability of the cells to uptake dsRNA from the culture media, further suggesting an important role for Sid-1 in dsRNA uptake [59]. C. elegans carries two additional sid-1 like genes, tag-13o (also known as $\mathrm{ZK}_{721.1}$ ) and $\mathrm{Y}_{37} \mathrm{H}_{2} \mathrm{C} 1$, although their functions are unclear. Many vertebrate species also have sid-1 homologs [53,92]. However, Drosophila, which does not show a robust systemic RNAi response, lacks sid-1-like genes, leading to the hypothesis that the presence or absence of a sid-1-like gene is the primary determinant of whether or not systemic RNAi occurs in an organism [28,53,92-94].

We have identified three sid-1-like genes in the Tribolium genome. We have decided to call these genes sil (sid1-like; TcsilA-C) instead of Tc-sid-1, because of uncertainty about the orthology of insect sid1-like genes to C. elegans sid-1 (see below). RT-PCR and RACE analyses have revealed the fulllength sequences (Tc-SilA, 764 amino acids; Tc-SilB, 732 amino acids; Tc-SilC, 768 amino acids, see Materials and methods for details). Like C. elegans Sid-1, all three proteins contain a long amino-terminal extracellular domain followed by 11 transmembrane domains predicted by TMHMM server version 2.o. InterProScan identified no additional motifs or domains.

To determine whether the presence of sil genes correlates with the presence of systemic RNAi in insects, we have searched the genome of several insects using the Tc-SilA protein sequence as a query (Table 1). The honeybee (Apis mellifera; Hymenoptera) and a parasitic wasp (Nasonia vitripennis; Hymenoptera) each contain a single sid-1-like 
Table I

Incidence of sil genes and systemic RNAi in insects

\begin{tabular}{|c|c|c|c|c|c|}
\hline \multirow[b]{2}{*}{ Species } & \multirow[b]{2}{*}{ sil gene number } & \multirow[b]{2}{*}{ Larval/nymphal } & \multicolumn{2}{|c|}{ Systemic RNAi } & \multirow[b]{2}{*}{ References } \\
\hline & & & Adult & Parental & \\
\hline Drosophila melanogaster & 0 & ND* & Some tissues ${ }^{\dagger}$ & Yes & {$[35,36,44]$} \\
\hline I2 Drosophilids & 0 & ND & ND & ND & \\
\hline Anopheles gambiae & 0 & ND & Some tissuest & No $\ddagger$ & {$[33,34]$} \\
\hline Aedes aegypti & 0 & ND & Some tissuest & ND & {$[34,37]$} \\
\hline Bombyx mori & 3 & Limited success§ & ND & ND & [45-48] \\
\hline Apis mellifera & 1 & Some tissues ${ }^{\dagger}$ & Some tissuest & ND & {$[32,38]$} \\
\hline Nasonia vitripennis & 1 & ND & ND & Yes & {$[4 \mid]$} \\
\hline Tribolium castaneum & 3 & Yest & Some tissuest & Yes & {$[27,40]$} \\
\hline Schistocerca americana & $\geq 1$ & Some tissues ${ }^{\dagger}$ & ND & ND & [28] \\
\hline
\end{tabular}

*Yes in hemocyte (SCM and YT, unpublished results). †RNAi has been successfully performed in some tissues (but not in other tissues). $¥$ Ovary can take up dsRNA, but parental RNAi has been unsuccessful (MGorman, personal comunication). §ST, unpublished data, R Futahashi and T Kusakabe, personal communications. IAll tissues are suceptible (SCM and YT, unpublished results). ND, not determined.

gene. The silkworm moth (B. mori; Lepidoptera) has three sid-1-like genes. We have determined the full-length sequences of these genes in Bombyx (see details in Materials and methods). As previously mentioned, D. melanogaster does not have any sid-1-like genes. We have confirmed that none of the 11 additional Drosophila species whose genomes have been sequenced carry sid-1 family genes. In addition, two mosquito species (Anopheles gambiae and Aedes aegypti) also lack sid-1-like genes, suggesting the early loss of sid-1-like genes in the dipteran lineage.

The presence of three sil genes in Tribolium is consistent with their hypothesized importance to a robust systemic RNAi response. It has also been shown that parental RNAi is possible in Nasonia [42], which is consistent with the presence of a sil gene in this insect. On the surface, the lack of sid-1-like genes in dipterans seems to correlate with the apparent lack of systemic RNAi response in these insects. However, reports that some tissues in Drosophila as well as in mosquitos are capable of taking up dsRNA [33-37,45] (MJ Gorman, personal communication) suggest that such correlations might be misleading. Moreover, Bombyx carries three sil genes, yet does not show a robust systemic RNAi response (S Tomita, unpublished data; R Futahashi and T Kusakabe, personal communications). This apparent breakdown in the correlation between systemic RNAi and sil genes (Table 1) raises the question of whether sid-1-like genes are the determinant of presence/absence of systemic RNAi in insects.

We have analyzed the expression of sil genes to provide a clue about the function of these genes in Tribolium. in situ hybridization analysis shows that all three sil genes are expressed uniformly in embryos; however, silA and silB seem to be expressed at lower levels than silC (data not shown). Semiquantitative RT-PCR reveals that all sil genes are expressed throughout all developmental stages (Additional data file 3).
silA and silB expression level is uniform through the larval to adult stages, while silC has peak expression at the pupal stage.

We have performed phylogenetic analyses using the carboxyterminal conserved region (the region corresponding to the second to tenth transmembrane domains; Additional data file 4) to solve the orthology of Sid1-like proteins. Both neighbour-joining and maximum-likelihood analyses produce the same tree with slightly different bootstrap values (see Figure 6 a for the neighbour-joining tree). In these trees, all three $C$. elegans proteins comprise a distinct cluster. Two of the Tribolium Sil proteins (Tc-SilA and Tc-SilB) also comprise a separate cluster, while Tc-SilC clusters with honeybee as well as vertebrate Sid-1-like proteins. Bombyx Sil proteins belong to this cluster; however, they comprise a distinct sub-cluster in this branch. This result is somewhat puzzling since it appears to suggest multiple occurrences of lineage-specific duplication. Alternatively, the expansion of sil genes might be ancient, but the paralogs might have been subjected to lineage specific parallel constraints (perhaps to target a species specific ligand), leading to convergent sequence similarity. The clustering of the three C. elegans homologs might be due to a long branch attraction caused by their highly diverged sequences. The clustering of vertebrate Sid-like proteins with Tc-SilC and the honeybee proteins might suggest a conserved function in this cluster.

Although the carboxy-terminal transmembrane region shows a high degree of identity between all Sid-1-like proteins, the amino-terminal extracellular region is less conserved (Additional data files 4 and 5). We noticed, however, that there are several segments in the extracellular region that are shared by insect and vertebrate Sid-1-like proteins (Figure 6b; see also Additional data file 5 for dot-matcher alignments). Interestingly, C. elegans Tag-130, but not Sid-1, also shares these amino-terminal motifs (Figure 6a, Additional data file 5), 
(a)

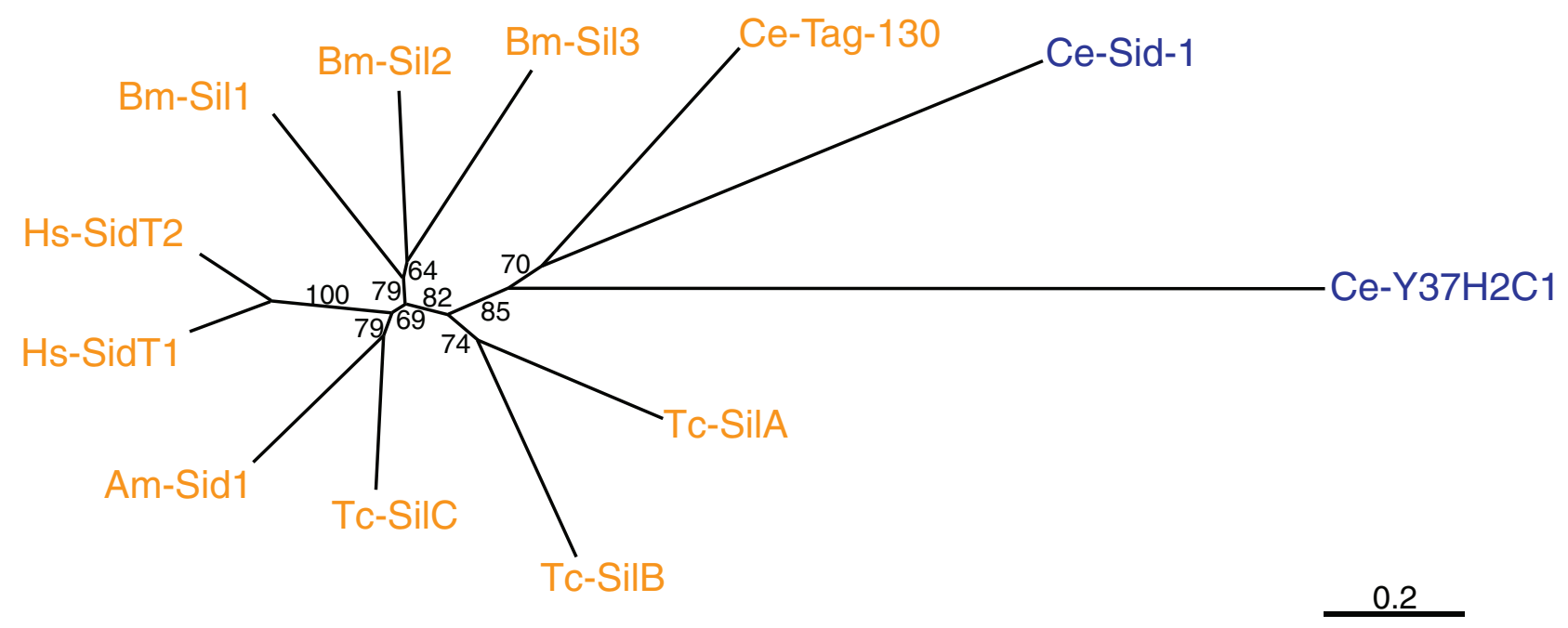

(b)

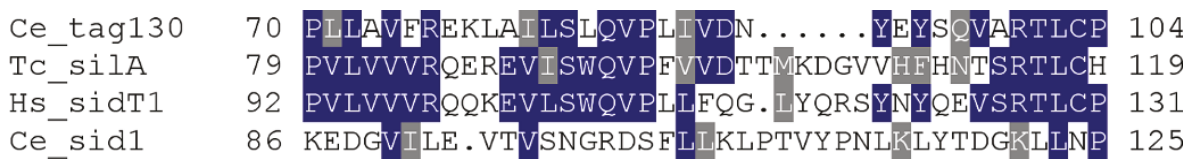

Ce_tag130 17

TC_SilA 210

Hs_sidT1 212

Ce_sid1 225

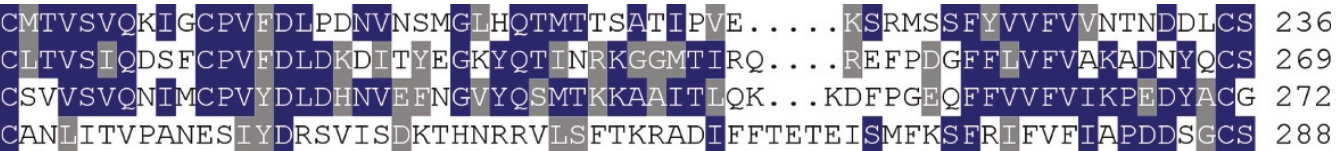

Figure 6

Sil protein alignment and phylogenetic analysis. (a) Phylogenetic analysis of Sid-I-like proteins. The neighbor-joining tree is based on the alignment of the carboxy-terminal transmembrane domain corresponding to the TM2-TMI I region of $C$. elegans Sid-I (Additional data files I and 4). Tc-SilC clusters with the human Sid-I-like proteins (SidTI and SidT2), while Tc-SilA and Tc-SilB compose a distinct cluster. Orthology of these insect and vertebrate Sid-I-like proteins to the $C$. elegans homologs is unclear from this analysis. Proteins that contain the amino-terminal conserved region are indicated in red. (b) Two conserved regions in the amino-terminal extracellular domain. These regions are conserved in vertebrate Sid-I-like proteins (represented by human SidTI), insect Sil proteins (Tc-SilA), and C. elegans Tag-I30, but not in C. elegans Sid-I.

raising questions about the orthology of insect/vertebrate Sid-like proteins and C. elegans Sid-1. Sil proteins in insects and vertebrates might instead be orthologous to $C$. elegans Tag-130.

Although our phylogenetic analysis is inconclusive on the orthology of insect Sil proteins, the sequence similarity of the amino-terminal extracellular region between Sil proteins and C. elegans Tag-130 suggests that these proteins may share similar functions. To gain further insight into the function of sil genes, we have analyzed whether tag-13o has any function in systemic RNAi in C. elegans. We obtained two deletion alleles of tag-13o from the Caenorhabditis Genetics Center. One allele, $\operatorname{tag}-130^{g k 245}$, has been described to have a $711 \mathrm{bp}$ deletion that removes the promoter region as well as the first $221 \mathrm{bp}$ of the coding region (73 amino acids) (Additional data file 6). We have confirmed this deletion by PCR. We have also

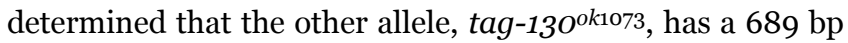
deletion spanning several exons that encode transmembrane domains (exons 14 to 17; see Additional data file 6 for the detailed deleted region). RT-PCR analysis has revealed that tag-130 ${ }^{\text {kk245 lacks } t a g-13 O}$ gene transcription, suggesting that this is a null allele. We have detected two different forms of

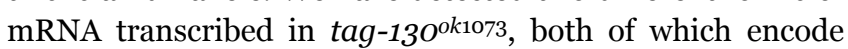
truncated proteins (Additional data file 6). These proteins lack several transmembrane domains, suggesting that tag$130^{o k 1073}$ is also a null allele. To determine whether these mutants are susceptible to systemic RNAi, we fed them unc22 dsRNA expressing $E$. coli. The N2 wild-type strain was used as a positive control, and sid-1 ${ }^{\text {sq2 }}$, a null allele for sid-1 [53,59], was used as a negative control. If $\operatorname{tag}-130$ is involved in systemic RNAi, mutations in the tag-13o gene should 
Table 2

\begin{tabular}{lcccc}
\hline Feeding RNAi in sid-I and tag- $\mathbf{3 0}$ mutants & & & \\
\hline Genotype & Total number & unc-22 & non-unc & $\%$ unc phenotype \\
\hline N2 (wild type) & 315 & 308 & 10 & $97.8 \%$ \\
tag-I30gk245 & $34 I$ & 340 & 1 & $99.7 \%$ \\
tag-I30k1073 & 140 & 138 & 2 & $98.6 \%$ \\
sid Isq2 & 297 & 0 & 297 & $0.0 \%$ \\
\end{tabular}

prevent the unc-22 RNAi twitching effect [95]. However, almost $100 \%$ of individuals carrying either tag-13o deletion allele show a twitching phenotype upon administration of unc-22 feeding RNAi, while none of the sid-1 individuals showed twitching (Table 2). These data indicate that tag-130 is not necessary for the systemic RNAi response in C. elegans. By extension, the greater sequence similarity of insect Sil proteins to Tag-130 than to Sid-1 suggests that Sil proteins might not be involved in systemic RNAi in Tribolium.

\section{C. elegans rsd gene homologs}

Another screen for C. elegans mutants lacking systemic RNAi led to the discovery of several additional genes involved in the systemic RNAi response, including rsd-2, rsd-3, and rsd-6 [6o]. Mutants for these genes still retain the systemic RNAi response in somatic cells, but germ-line cells lack the ability to respond to dsRNA [6o]. The Rsd-2 protein contains no particular motifs, while Rsd-6 has a Tudor domain, which is found in some RNA binding proteins [6o]. A yeast two-hybrid analysis found that Rsd-2 interacts directly with Rsd-6, suggesting that these proteins act together [6o]. We do not find Tribolium homologs for rsd-2 or rsd-6 in the genomic sequence of Tribolium (Table 3) or in several other insects whose genomes have been sequenced, which suggests that the Rsd-2/Rsd-6 system is either not conserved in insects, or is evolving too rapidly to be detected across long evolutionary distances.

The third gene, $r s d-3$, encodes a protein that contains an epsin amino-terminal homology (ENTH) domain [6o].
ENTH domains are often found in proteins involved in vesicle trafficking, suggesting the possible involvement of endocytosis in systemic RNAi [60]. We found a homolog for Rsd-3 in Tribolium (Tc-Rsd3). Drosophila also carries a protein similar to Rsd-3 (Epsin-like).

In addition, the Rsd-3 protein has a close relative in $C$. elegans, Epn-1, whose Drosophila counterpart (Liquid Facets; Lqf) has been reported to be involved in Notch signaling [9698]. We found a Tribolium ortholog for Epn-1/Lqf, which we named Tc-Lqf. Although there is no report implying the involvement of Epn-1/Lqf family proteins in systemic RNAi, their high degree of identity with Rsd-3 proteins suggest that such a role is possible.

Since Drosophila (which seems to lack a systemic RNAi response) also carries Rsd-3-like proteins (Table 3), it does not seem likely that these proteins determine the presence or absence of systemic RNAi in insects. However, it might be still possible that the expression level and/or tissue specificity of rsd-3-like genes affect the degree of RNAi efficiency.

\section{Endocytosis components and scavenger receptors}

Another piece of evidence that suggests the involvement of endocytosis in dsRNA uptake comes from a study using Drosophila S2 culture cells [61,62]. Among the factors identified in this study as necessary for dsRNA uptake are a number of proteins whose functions are implicated in endocytosis $[61,62]$ (Table 4). Also, several scavenger receptors, such as Eater and $\mathrm{Sr}-\mathrm{CI}$, were found to be important for dsRNA

Table 3

Candidates based on systemic RNAi genes found in C. elegans

\begin{tabular}{lllll}
\hline Gene name & Ce gene ID & Tc gene ID & Biological function & Reference \\
\hline Sid-I & CO4F5.I & 11760 & Systemic RNAi (somatic cells) & [53] \\
& & 06161 & & \\
Rsd-2 & 15033 & & & \\
Rsd-3 & F52G2.2 & & Systemic RNAi (germ cells) & {$[54]$} \\
Epn-I* & C34EII.I & 12168 & Systemic RNAi (germ cells) & \\
Rsd-6 & T04CI0.2 & 05393 & Endocytic protein (EPsiN) & Systemic RNAi (germ cells) \\
\hline
\end{tabular}

* Related to Rsd-3. Ce: Caenorhabditis elegans. Tc: Tribolium castaneum. 
Table 4

\begin{tabular}{|c|c|c|c|c|}
\hline Gene name & Dm gene ID & Tc gene ID & Biological function & Reference \\
\hline $\operatorname{Ar} 72 A$ & CG6025 & 08443 & Endosome transport & [62] \\
\hline AP 50 & CG7057 & 11923 & Endocytosis & [62] \\
\hline Clathrin he & CG9012 & 15014 & Endocytosis & [62] \\
\hline$I d I C P$ & CG6177 & 10886 & Exocytosis & {$[62]$} \\
\hline Light & CGI8028 & 15204 & Lysosomal transport & [62] \\
\hline Nina C & CG54I 25 & 14087 & Rhodopsin mediated signaling & {$[62]$} \\
\hline Rab 7 & CG5915 & 06036 & Endosome transport & {$[62]$} \\
\hline Eater & CG6124 & XP_969372* & Inate immune response/phagocytosis & {$[61]$} \\
\hline $\mathrm{Sr}-\mathrm{Cl}$ & CG4099 & & Inate immune response/phagocytosis & {$[61]$} \\
\hline Sr-Cll & CG8856 & 15640 & Inate immune response/phagocytosis & {$[61]$} \\
\hline Sr-CIII & CG31962 & & Inate immune response/phagocytosis & {$[61]$} \\
\hline $\mathrm{Sr}-\mathrm{CIV}$ & CG3212 & & Inate immune response/phagocytosis & {$[61]$} \\
\hline Vhal6 & CG316I & 11025 & ATP synthase/ATPase & {$[62]$} \\
\hline VhaSFD & CGI7332 & 06281 & ATP synthase/ATPase & [62] \\
\hline Gmer & CG3495 & 14956 & Metabolism & {$[62]$} \\
\hline$P I 3 K 59 F$ & CG5373 & 00620 & Lipid metabolism & {$[62]$} \\
\hline Saposin $r$ & CGI2070 & 00449 & Lipid metabolism & [62] \\
\hline \multirow[t]{11}{*}{ Egghead } & CG9659 & 08154 & Oogenesis & {$[62]$} \\
\hline & CG4572 & 02692 & Peptidase & [62] \\
\hline & CG5053 & 07768 & Signal transduction & {$[62]$} \\
\hline & CG8I84 & 04152 & Ubiquitin ligase & {$[62]$} \\
\hline & CG8773 & 16254 & Peptidase & {$[62]$} \\
\hline & CG5382 & 09067 & Zinc finger transcription factor & {$[62]$} \\
\hline & CG5434 & 12172 & Translation regulation & {$[62]$} \\
\hline & CG3248 & 12410 & Unknown & [62] \\
\hline & CG391I & 14009 & Unknown & {$[62]$} \\
\hline & CG867I & 04825 & Unknown & {$[62]$} \\
\hline & CG5I6I & 07973 & Unknown & {$[62]$} \\
\hline
\end{tabular}

*XP_969372 is a NCBI prediction that partially matches Tc_02053; however, Tc_02053 seems to be a chimera of at least three genes. Dm: Drosophila melanogasater. Tc: Tribolium castaneum.

uptake $[61,62]$ (Table 4). Scavenger receptors are known to act as receptors for large molecules and/or microbes (for a review of scavenger receptors, see [99]). Since these receptors act in phagocytosis, a type of endocytosis, they could potentially act as receptors for dsRNA molecules in an endocytic process. Although the factors identified in S2 cells might reflect mechanisms of dsRNA uptake specific to hemocytelike cells [100], it is possible that some of them function in other tissues as well.

We have identified the Tribolium orthologs of these genes (Table 4). In many cases, they show clear one-to-one orthology. In the case of $S r-C I$, however, we found only one Tribolium homolog ( $\mathrm{Tc}-\mathrm{Sr}-\mathrm{C})$, in contrast to four closely related paralogs in Drosophila [100]. The case of eater is even more complicated. eater encodes a Nimrod family protein that contains multiple NIM-type EGF domains [101,102]. A BLAST search using Drosophila Eater (CG6124) identifies several predicted Tribolium proteins that contain NIM repeats. Among them, an NCBI predicted protein (XP_969372) and Eater are reciprocal best hits, suggesting that they might be orthologous. However, the similarities among Nimrod family proteins in both insects make it difficult to assign orthology. Detailed sequence analysis will be required to definitively determine the orthology of these genes.

As in the case of $r s d-3$, the fact that both Drosophila and Tribolium carry these genes might suggest that these factors do not determine the presence or absence of systemic RNAi in insects. Yet, it is still possible that a difference in tissue specificity and/or expression level might affect the efficiency of dsRNA uptake from the outside environment. Expression analysis of these genes might help determine whether these factors are broadly involved in dsRNA uptake in insects. 


\section{Functional analysis of Dicer, Argonaute, and Sil genes in Tribolium}

To further understand the RNAi mechanism in Tribolium, we have developed an assay system to assess the involvement of genes in the RNAi pathway in vivo. This system takes advantage of an enhancer trap line (Pu11), which expresses enhanced green fluorescence protein (EGFP) in the eyes and in the future wing primordia (Figure 7a, b). We previously reported that the RNAi effect can be monitored by the intensity of EGFP fluorescence in the Pu11 line after EGFP RNAi [27]. Our assay system is composed of three steps (Figure 7a): first, RNAi for a gene of interest at the early last larval stage, prior to the onset of wing EGFP expression in Pu11; second, RNAi for EGFP two days after the initial injection; and third, monitoring of the EGFP expression at the prepupal and midpupal stages when Pu11 EGFP expression is most intensified. In this assay system, the efficiency of EGFP RNAi would be reduced (therefore, EGFP expression would be visible) if the gene knocked down at the first step is involved in the RNAi pathway. In contrast, EGFP expression would be silenced if the initially knocked down gene is not involved in the RNAi pathway. In order to maximize the sensitivity of this test, the initial RNAi is done at a high concentration $(1 \mu \mathrm{g} / \mu \mathrm{l}$, approximately $0.5 \mu \mathrm{g} /$ larva) while the second RNAi for EFGP is performed at a lower concentration $(10 \mathrm{ng} / \mu \mathrm{l}$, approximately $5 \mathrm{ng} /$ larva). This low concentration of EGFP dsRNA is enough to completely silence EGFP expression ( $n=147$; Figure $7 \mathrm{c}$ ) when injected alone. A potential caveat of this system is that injection of the initial dsRNA might saturate the RNAi machinery and prevent the effect of the secondary RNAi in a non-specific manner. In this case, a low concentration of the secondary dsRNA might exacerbate the problem.

To rule out such a problem, we first tested our assay system with genes that are not involved in the RNAi pathway. dsRNA for dsRed (an exogenous gene) was injected prior to EGFP RNAi, which resulted in complete silencing of EGFP ( $n=27$; Figure $7 \mathrm{~d}$ ). We also used Tc-Ultrabithorax (Tc-Ubx) as a control for an endogenous gene. Tc-Ubx RNAi induced a hindwing to elytron transformation as described before [103], but did not affect the EGFP silencing (Figure 7e). The prior injection of dsRNA for either an exogenous or an endogenous gene did not affect the effectiveness of EGFP RNAi, indicating that our assay system does not have a competition problem.

One of the findings through our genome-wide survey for RNAi genes in the Tribolium genome is that Tribolium has more RNAi component genes than Drosophila, which might make Tribolium more sensitive to dsRNA. We have cloned the Tribolium Argonaute and Dicer genes and tested whether these genes are actually involved in the RNAi pathway. We found that RNAi for Dcr-2 decreases the effectiveness of subsequent EGFP RNAi (Figure 8b; 10 of 17 individuals show EGFP expression), indicating that Dcr-2 is important for the RNAi pathway. However, contrary to our analysis of the Dcr1 protein domain architecture (which suggests the possible involvement of $D c r-1$ in the RNAi pathway), RNAi for $D c r-1$ had no effect on EGFP RNAi ( $n=32$; Figure 8a), and did not enhance the effect of the Dcr-2 RNAi in the Dcr-1/2 double RNAi (Figure 8c; 12 of 30 show EGFP expression). Instead, Dcr-1 RNAi shows an occasional wing expansion defect (3 of 20), suggesting that Dcr-1 is involved in wing development, most likely through the miRNA pathway.

Of the three Tribolium Argonaute genes, we found that both Ago-2 genes are involved in the RNAi pathway (Figure 8e-g; 8 of 28 Ago-2a RNAi and 12 of 28 Ago- $2 b$ individuals show EGFP expression). This is in line with our hypothesis, and indicates that Tribolium indeed has duplicated Argonaute genes that are functional in the RNAi pathway. Larvae injected with Ago-1 dsRNA show developmental defects and fail to pupate, but still exhibit efficient $E G F P$ silencing (Figure $8 \mathrm{~d} ; n=21$ ). This result suggests that $A g o-1$ is involved in the miRNA pathway, but not in the RNAi pathway.

We also tested whether the Tribolium sil genes are involved in the RNAi pathway. Neither the single RNAi for each sil gene nor the triple RNAi shows any effect on subsequent EGFP RNAi (Figure 8h-k), suggesting that the sil genes are not involved in systemic RNAi in Tribolium. This result is consistent with our tag-13o deletion mutant analysis in C. elegans. However, this result must be interpreted with caution since triple RNAi might weaken the RNAi effect on the sil genes (see Discussion).

\section{Discussion}

RNAi techniques have had tremendous impact on many biological fields. In many organisms, RNAi allows loss-of-function phenotypes to be analyzed in the absence of mutants. In some organisms such as Tribolium, simple injection of dsRNA into the larval or pupal body cavity can induce the RNAi response systemically [27,41]. However, some organisms (such as many lepidopteran [46]) lack the ability to respond to dsRNA systemically. Understanding the molecular basis of systemic RNAi might help us apply systemic RNAi-based methods to these insects.

Tribolium, which is a highly established genetic model system, has a robust systemic response to dsRNA, giving us an opportunity to explore the molecular mechanism for systemic RNAi in an animal other than C. elegans. In this study, we have surveyed the Tribolium genome for the genes that encode RNAi core components, as well as the genes that have been implicated in systemic RNAi. If the mechanism for systemic RNAi is conserved between C. elegans and insects, we would expect to find a component that is present in C. elegans and Tribolium but not in Drosophila. However, we find a surprisingly low degree of conservation between the $C$. elegans and Tribolium gene inventories. 


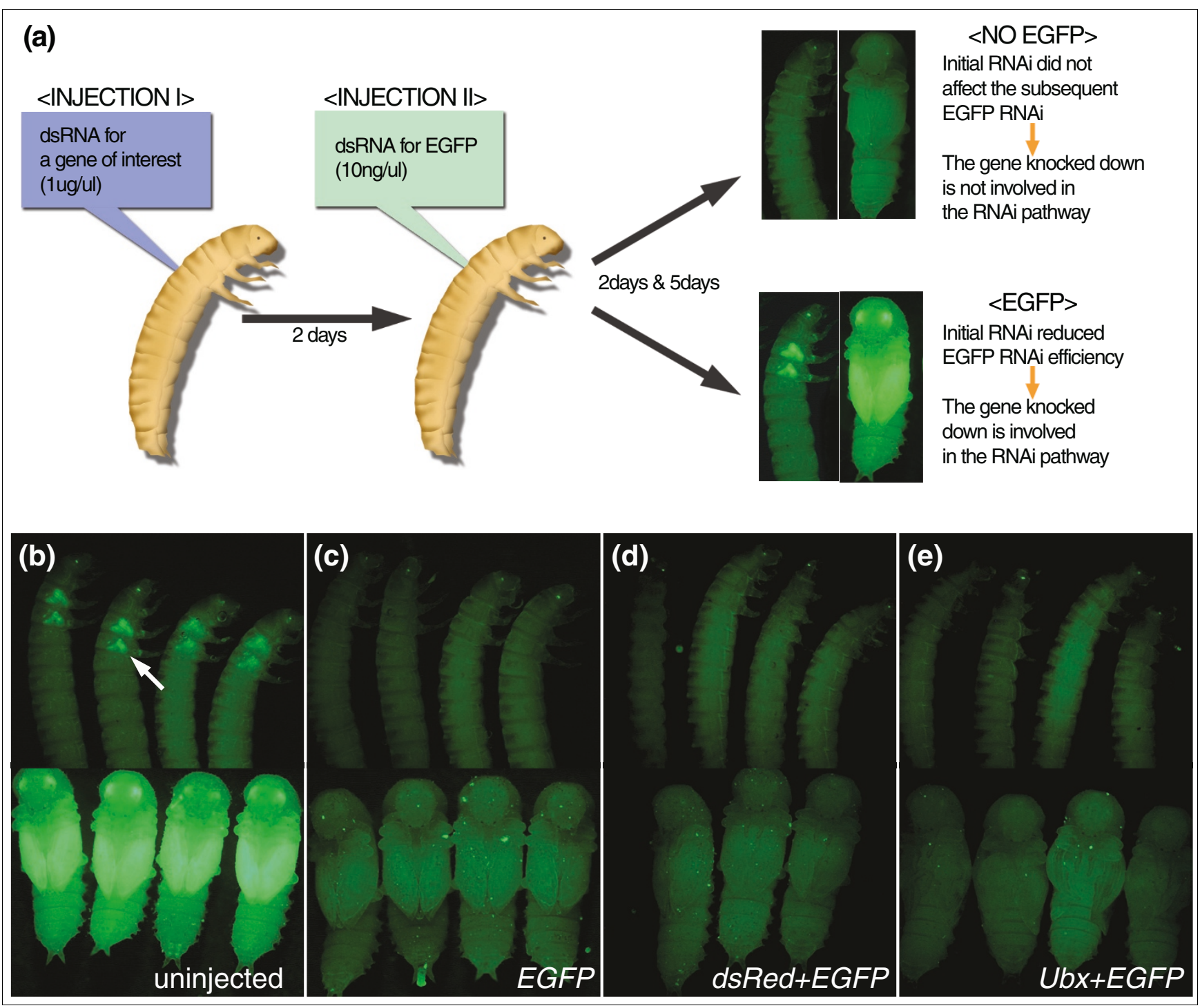

\section{Figure 7}

An in vivo assay system for RNAi genes in Tribolium. (a) A scheme of the in vivo assay system for RNAi genes. (b) Uninjected Pul I larvae and pupae. EGFP is expressed in the wing primordia (arrow) at the larval stage, as well as in the pupal wings. EGFP is also expressed in the eye. (c) EGFP dsRNA-injected larvae and pupae. EGFP expression is completely silenced. (d, e) Larvae and pupae that were injected with dsRNA for dsRed (d) or Tc-Ubx (e) prior to the secondary EGFP RNAi. The prior injection of dsRNA for these genes does not affect the effectiveness of EGFP RNAi. Tc-Ubx RNAi pupae show hindwing to elytron transformation (e), indicating that the RNAi is working properly.

In the following section, we discuss our results in the context of three steps that might be important for systemic RNAi: the cellular uptake of dsRNA; the amplification and maintenance of dsRNA; and an efficient RNAi response.

The dsRNA uptake mechanism is not highly conserved For a systemic response, cells must first take up dsRNA from their environment. Several proteins responsible for dsRNA uptake have been discovered in C. elegans. The best described is Sid-1, which can confer the ability to import dsRNA to Drosophila cells in a cell culture environment [59]. The finding of three sid-1 homologs in Tribolium but none in Drosophila appears on the surface to be a convincing explanation for the ostensible lack of systemic RNAi in Drosophila.

We challenge this assumption with two lines of evidence. The first evidence comes from the fact that all sid-1 homologs in Tribolium (and other organisms) have more identity with another C. elegans gene, tag-130, than with sid-1. Importantly, these proteins share several blocks of identity in the extracellular amino-terminal domain that are not present in $C$ elegans Sid-1. Since the extracellular domain is likely important for ligand specificity, this conservation suggests that the function of Sil proteins in Tribolium might be more similar to that of Tag-130 than Sid-1. Further, we have shown 


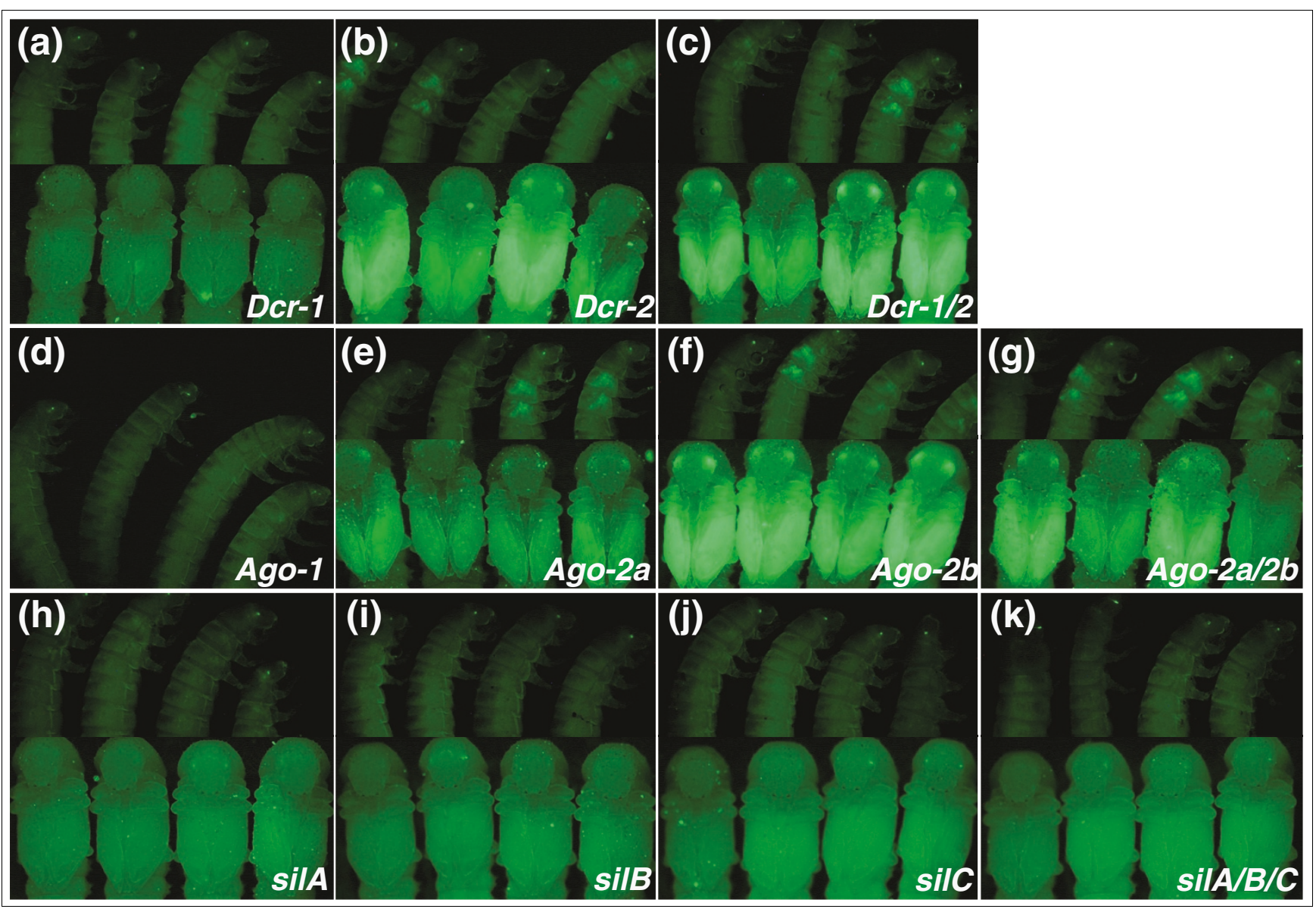

Figure 8

Functional analysis of Dicer, Argonaute, and sil genes in Tribolium. Larvae and pupae that were injected with dsRNA for (a-c) Dicer, (d-g) Argonaute, or (h-k) sil genes prior to EGFP RNAi. RNAi for Dcr-2, Ago-2a, or Ago-2b reduces the efficiency of EGFP RNAi (b, c, e-g). In contrast, RNAi for Dcr-I, Ago-I, or sil genes does not affect EGFP RNAi (a, d, h-k).

that the tag-13o gene is not required for systemic RNAi in $C$. elegans. These data raise the possibility that the dsRNA uptake function of sid-1 has evolved in a nematode lineage, and is not an ancestral feature of tag-13o homologs. C. elegans is known to exhibit an exceptionally high rate of amino acid change [104]. The long branch of C. elegans Sid-1 in the phylogenetic tree might support the idea that Sid-1 has diverged quickly, and gained a function that is not conserved in other organisms.

The second line of evidence comes from the apparent breakdown in the correlation between systemic RNAi and sil genes (Table 1). We note that the silkworm moth, B. mori, has similar sil genes but efforts to apply systemic RNAi on this species have been unsuccessful (S Tomita, unpublished data; R Futahashi and T Kusakabe, personal communications; but also see [47-49] for some successes). In contrast, some tissues in adult dipterans have been shown to be capable of taking up dsRNA [33-37,105], although these insects lack sid-1-like genes. Parental RNAi has also been performed successfully in Drosophila [45,106]. In addition, the parasitic nematode spe- cies Haemonchus contortus shows an ability to respond to soaking RNAi [107], but sid-1/tag-13o related genes can not be found in its sequenced genome [107] (data not shown).

Taken together, these observations suggest that a Sid-1-based mechanism is not the only existing method of dsRNA uptake. Triple RNAi for the three sil genes does not affect subsequent RNAi for EGFP (Figure 8h-k), suggesting that sil genes are dispensable for systemic RNAi in Tribolium. However, the use of multiple RNAi complicates interpretation of this result. Competition for RNAi components by multiple dsRNA triggers is known to weaken the efficiency of RNAi in C. elegans [83] as well as in Tribolium (SCM and YT, unpublished data). Thus, it is still possible that sil genes are required for systemic RNAi, but that the competition produced by triple RNAi results in incomplete knockdown of the sil genes. The stability of Sil proteins could also affect our assay. Some amount of the Sil proteins might stay functional even two days after knockdown of the sil genes. In these cases, the systemic RNAi pathway would retain some function. While the above concerns need to be considered, we do see a delay in larval develop- 
ment in the triple sil RNAi (data not shown), but not in each single RNAi. This might suggest that the triple RNAi is efficiently removing sil gene function. Further functional analysis, such as attempts to rescue $C$. elegans sid-1 mutants with Tribolium sil genes, or overexpression of sil genes in Drosophila culture cells, might reveal whether insect Sil proteins are capable of promoting dsRNA uptake.

Three more genes, $r s d-2, r s d-3$, and $r s d-6$, have been identified as important factors for the systemic RNAi response in germline cells in C. elegans [6o]. Two of them, rsd-2 and rsd6 , are either not present in the Tribolium genome or their sequence is rapidly evolving such that homology cannot be detected over long evolutionary distances. Only rsd-3 has a clear ortholog in Tribolium (Tc-epsin-like). However, Drosophila also has an epsin-like gene but does not show clear systemic RNAi. Either the gene is not sufficient to confer enough dsRNA uptake for systemic RNAi or the expression of this gene is more restricted in Drosophila.

In summary, the genes required for systemic RNAi in C. elegans are not highly conserved in Tribolium. These findings contradict the recent suggestion that the presence of sid-1 like genes is sufficient for a systemic RNAi response in an organism [28,53,93]. A different mechanism for dsRNA uptake, such as an endocytosis-based mechanism, might await discovery in Tribolium.

\section{The C. elegans RNAi amplification mechanism is not present in Tribolium}

In C. elegans (as well as in plants and fungi), RdRP amplifies the RNAi effect $[19,20]$. This amplification is apparently absolutely necessary for the RNAi response in C. elegans, as RdRP mutants are insensitive to dsRNA $[19,20]$. The robust RNAi response in Tribolium might be due to an amplification mechanism similar to that in C. elegans. However, we do not find RdRP in Tribolium. Although we cannot exclude the possibility that an RdRP gene is located in the non-sequenced part of the Tribolium genome, this possibility is unlikely for several reasons. First, RdRP genes do not seem to be present in most animals (see the 'Absence of RNA-dependent RNA polymerase in Tribolium' section). Second, RdRP-amplified siRNAs are associated with a specific class of Argonautes (secondary Argonautes) in the two-step RNAi mechanism of $C$. elegans, but secondary Argonautes are not conserved in Tribolium. And third, in Tribolium, it is possible to target a particular isoform of a gene by RNAi, even when it shares more upstream sequence with other isoforms (lack of transitive RNAi) [108]. This indicates that there is no RdRP activity in Tribolium, since such activity would result in production of siRNAs corresponding to the region upstream (and perhaps even downstream) of the initial dsRNA target site and the knockdown of all messages sharing the upstream sequence. If there is an RNAi amplification step in Tribolium, it must be based on a different mechanism.

\section{The Tribolium RNAi machinery could be more efficient than that of Drosophila}

The inventories of genes involved in systemic RNAi and amplification do not show clear differences between Tribolium and Drosophila that would explain the presence and absence of systemic RNAi. An alternative hypothesis is that the core machineries for RNAi might function with different efficiencies in these species. Our genomic survey for RNAi core components has indeed revealed several differences in the number of these core component genes between Tribolium and Drosophila. Drosophila carries only one Ago-2 gene, while the Tribolium genome has two, apparently due to a lineage-specific duplication. We have shown that both Tribolium Ago-2 genes are involved in the RNAi pathway (Figure $8 \mathrm{~d}-\mathrm{g}$ ). As the availability of Ago proteins has been shown to determine the RNAi efficiency [80], it is quite possible that the Ago-2 copy number allows a more efficient RNAi response in Tribolium than in Drosophila.

There are also interesting differences between Dicer proteins. Dicer proteins can be involved in both RNAi and miRNA pathways [7]. For example, Dcr-1 protein in C. elegans functions in both pathways $[67,69]$. In Drosophila, however, a subfunctionalization seems to have happened between the two Dicer genes; one Dicer (Dcr-1) works specifically in the miRNA pathway, while the other (Dcr-2) functions in the RNAi pathway [17]. Each of these Dicer proteins has unique domain losses [17] (Figure 1c). One of the Tribolium Dicer proteins, Tc-Dcr-2, has similar domain architecture to Drosophila Dcr-2, suggesting that Tc-Dcr-2 is involved in the RNAi pathway. In contrast, Tc-Dcr-1 has an amino-terminal helicase domain, which is lacking in Dm-Dcr-1. This makes the domain architecture of Tc-Dcr-1 more similar to C. elegans Dcr-1, which might suggest that, in addition to Dcr-2, Dcr-1 could also be involved in the RNAi pathway in Tribolium. Our assay system provided no evidence that Dcr-1 is also involved in the RNAi pathway (Figure 8a). However, Dcr-1 RNAi does produce developmental defects. This could be due to defects in the miRNA pathway, since miRNAs play a crucial role in development in Drosophila and other organisms [109]. We noticed that the Dcr-1 RNAi phenotype is weaker than that of Ago-1, which is also likely to be involved in the miRNA pathway. This difference suggests that there might be another factor that acts redundantly with Dcr-1. This redundancy might also influence the Dcr-1 function in the RNAi pathway, leaving open the possibility that Dcr-1 is involved in the RNAi pathway but that its RNAi effect is masked in our assay system by a redundant factor. Dcr-2 is not the redundant factor since the $D c r-1 / 2$ double RNAi phenotype is still weaker than that of Ago-1. Further functional analysis is necessary to unravel the involvement of Dicer genes in the RNAi pathway in Tribolium.

In line with this, the Tribolium genome contains an additional R2D2-like dsRBM gene compared to Drosophila. $R 2 D 2$ determines the specificity of Dicers in Drosophila; Dcr- 
1 can associate with siRNA in R2D2 mutants [11,14]. An additional R2D2 in Tribolium, with C. elegans-type Tc-Dcr-1, might contribute to the robust RNAi response in Tribolium. Alternatively, since dsRBM proteins are known to bind to dsRNA, they might be involved in the maintenance of dsRNA in cells. In that case, the presence of an additional dsRBM protein might allow a longer-lasting RNAi effect. Intriguingly, it has been suggested that an ATP-dependent mechanism might be involved in retaining dsRNA inside cells in $C$. elegans [59], implying the existence of a yet to be found dsRNA maintenance mechanism.

These differences in core RNAi components might allow Tribolium cells to respond to dsRNA more sensitively than Drosophila cells. Further functional analysis is necessary to understand the molecular mechanism underlying the systemic RNAi response in Tribolium, as well as the evolutionary changes that caused the difference in ability of Tribolium and Drosophila to respond to dsRNAsystemically.

\section{Ancestral gene set for RNAi machinery}

Our genome-wide survey for RNAi genes has revealed that the repertoire of RNAi genes has been diversified even among insect species. Although the comparison between Tribolium, Drosophila, and C. elegans has clearly illuminated diversity in the inventory of RNAi component genes (Additional data file 8), more species will be necessary for the reconstruction of an ancestral RNAi gene set. The RNAi pathway is conserved not only in animals but also among many eukaryotes such as fungi, plants, and protists [2,110,111]. Phylogenetic analysis including diverse species might shed light on understanding the ancestral gene set and evolution of RNAi machinery.

\section{Conclusion}

Our analysis does not find a highly conserved mechanism for systemic RNAi between C. elegans and Tribolium. Insect systemic RNAi is likely, therefore, to be based on a different mechanism that remains to be uncovered. Understanding this process would assist with rendering other insects amenable to systemic RNAi, which in many cases is a prerequisite for functional gene analysis. In addition, knowing the mechanism of systemic RNAi in insects is likely to influence approaches of pest control in which dsRNAs are produced by a host plant. With its robust systemic RNAi response [27,41], recently sequenced genome [66] and available genetic tools [112-119], Tribolium offers an excellent opportunity to uncover the molecular basis of systemic RNAi in insects.

\section{Materials and methods Manual curation of automatically annotated Tribolium genes}

Tribolium homologs were identified by BLAST search at BeetleBase [120], and the corresponding predicted protein sequences were obtained from the Tribolium castaneum Genome Project website at the Baylor College of Medicine website [121]. These sequences were used for dot-plot analyses [122] and ClustalW alignments with Drosophila and other orthologs. Predicted exons that showed no identity to other orthologs were deleted. Conversely, when the Tribolium predictions were missing regions conserved in other orthologs, we searched the appropriate region of Tribolium genomic sequence for exons missed by the predictions.

\section{Phylogenetic analysis}

Multiple alignments were created and curated in MEGA 3.1 (Additional data file 1) [123]. Neighbour-joining analysis was performed in MEGA 3.1 with bootstrapping using 1,500 or 5,000 replicates. The same alignments were also used in TreePuzzle for maximum likelihood analysis [123,124] using standard settings. The trees were visualized using TreeView [125]. Both types of analysis resulted in essentially the same relationships.

The following conserved domains were used to create multiple alignments: Piwi domain for Argonaute proteins; first RNaseI domain for the Dicer protein alignment including Drosha; full-length except for dsRBM for the Dicer protein alignment without Drosha; tandem dsRBM for R2D2/Loquacious/Pasha; RdRP domain for RdRP proteins; exonuclease domain for Eri-1-like exonuclease; and multiple transmembrane domain (corresponds to TM2-TM11 portion of C. elegans Sid-1) for Sid-1-like proteins (Additional data file 1).

\section{Search for RdRP orthologs}

$S$. pombe RdP1 and C. elegans Ego proteins were used as the query in a tBLASTn search of the NCBI database (first searching all organisms and subsequently restricted to Eukaryota and then to Metazoa) to identify RdRP homologs. Sequenced nematode genomes were also searched at Nematode.net [126]. Viral RdRPs were excluded from the analysis, since they were not identified by these searches and ClustalW did not produce reasonable alignments of eukaryotic and viral RdRPs.

\section{Domain analysis}

Domain architecture of Dicer proteins was analyzed by ScanProsite [72,.127]. The scores for each protein domain presented in Figure 1c are similarity scores produced by a PROSITE search. A query sequence is compared to the PROSITE protein domain database. Domains are represented as a 'profile', which is a table of position-specific amino acid weights and gap costs. These numbers are used to calculate a similarity score for any alignment between a profile and a sequence. An alignment with a similarity score higher than or equal to a given cut-off value indicates a motif occurrence. Similarity scores below 8.5 are typically (but not for all profiles) regarded as questionable. See details at the PROSITE website [128]. Sid-1-like proteins were analyzed by TMHMM server v2.o [129] and InterProScan [130]. 


\section{Cloning genes}

Total RNA was isolated from Tribolium pupae (or adult Drosophila in the case of Dm-Ago3) using the RNeasy Protect Mini Kit (Qiagen, Valencia, CA, US), and cDNA was synthesized with SuperScript III (Invitrogen, Carlsbad, CA, USA) using oligo dT primer. Primers for Tc-sil genes and Tcsnp were designed based on the conserved domains identified by BLASTx analysis using Ce-Sid-1 and Ce-Eri-1, respectively. Primers for Argonaute and Dicer genes were designed based on conserved domains identified by BLASTx analysis using Drosophila homologs. Subsequent RACE analysis was performed using the GeneRacer kit (Invitrogen) on mRNA isolated from Tribolium pupae by the QuickPrep micro mRNA Purification Kit (GE Healthcare Bioscience, Piscataway, NJ, USA).

\section{Isolation of Bombyx sil genes}

Silkworm whole genome shotgun contigs and scaffolds at KAIKObase [131] were searched with tBLASTn using Tc-sil genes as queries. Three scaffolds, 000945, 000542 and 002595, were revealed to contain conserved domains. Primers were designed based on the sequences of these scaffolds and partial cDNAs were amplified by RT-PCR using mRNA isolated from Bombyx eggs at 72-120 hours after oviposition. Full-length cDNA clones were isolated and sequenced by screening cDNA libraries made from eggs 40 hours after oviposion [132] and midgut of the fifth instar day-2 larva (gift from Dr Kazuei Mita, National Institute of Agrobiological Sciences, Japan) with the partial cDNAs as probes.

\section{Semi-quantitative RT-PCR}

cDNA was synthesized with SuperScript III (Invitrogen) using mRNA isolated from five developmental stages (o-72 hour embryos, third/fourth instar larvae, last instar larvae, pupae, and adults). PCR was performed using Ex-Taq polymerase (Takara Bio USA, Madison, WI, USA). Reactions were performed with a varying number of cycles to ensure that comparisons were made within the linear range.

\section{C. elegans mutant strains and feeding RNAi}

Two tag-13O alleles, tag-130gk245 (strain name: VC452, created by the C. elegans Reverse Genetics Core Facility at UBC) and tag-130 OK1073 (RB1095, created by the C. elegans Gene Knockout Project at OMRF) were obtained from the Caenorhabditis Genetic Center at the University of Minnesota. The sid-1 ${ }^{s q 2}$ strain and unc-22 feeding RNAi Escherichia coli strain were the kind gift of Dr K Morita and Dr M Han (University of Colorado at Boulder, USA). Feeding RNAi was performed as previously described by Kamath et al. [133], and the unc-22 twitching RNAi phenotype was scored under a stereomicroscope. Four independent replicates of the feeding experiment were performed for each genotype.

\section{tag- I 30 mutant lesion}

Genomic DNA was isolated from tag-130 mutants (as well as N2 and sid-1 ${ }^{s q 2}$ strains) by adapting a protocol for isolation of genomic DNA from a single Drosophila adult [134]. To determine the deleted region, five sets of primers that together cover the entire tag-13O gene were used to survey the tag-13O locus. We used [gk245iF1:gtgcatcgtatgagcetgtg]/ [gk245iR1:aattgttgcagacgtggtca] and [OK1073D F1:ctaggtgcaatcagtgagccagtg]/[OK1073E R1:ataaaattccggcacaagtccag] to amplify the genomic region that contains the deleted region in tag-130 gk245 and tag-130 OK1073, respectively. PCR products were then cloned into pCR4-TOPO using the TOPO TA-Cloning Kit for Sequencing (Invitrogen), and sequenced to determine the deleted region [GenBank: EF695395, EF695396]. Total RNA was isolated from tag-130 mutants and the sid-1 ${ }^{s q 2}$ and N2 strains using the RNeasy Protect Mini Kit (Qiagen), and cDNA was synthesized with SuperScript III (Invitrogen) using oligo dT primer. We used [tag130cDNA F2:aagagcgtatacacatttggaaga] and [tag130cDNA R3:attacattgatggcggtgaaa] for RT-PCR. We detected two different transcripts in tag-130 ${ }^{O K 1073}$, both of which were cloned into pCR4-TOPO and sequenced [GenBank: EF695397, EF695398].

\section{dsRNA synthesis and larval injection in Tribolium}

A PCR amplified fragment of each gene was cloned into pCR4-TOPO using the TOPO TA Cloning Kit for Sequencing (Invitorogen). Primers used to amplify gene fragments and the size of each fragment are summarized in Additional data file 9. Templates for in vitro transcription were prepared by PCR using a primer designed to prime on two pCR4-TOPO vector regions that flank the inserted gene fragment [TOPO_RNAi_T7:taatacgactcactatagggcgaattcgccett]. This primer amplifies a gene fragment with the $\mathrm{T} 7$ polymerase promoter site at both ends. Gene specific primers with the $\mathrm{T}_{7}$ sequence at their 5 ' end were used to create a EGFP dsRNA template $(520 \mathrm{bp})$ [GFPiF2:taatacgactcactatagggcgatgccacct, GFPiR5: taatacgactcactatagggeggactgggtg] (the $\mathrm{T}_{7}$ site is underlined). dsRNA synthesis (using an Ambion MEGAscript T7 High Yield Transcription Kit. Ambion, Austin, TX, US) and larval injection were performed as described previously [27]. Larvae and pupae were documented using an Olympus SZX12 microscope with Nikon DXM $1200 F$ digital camera. The same exposure time ( $1 / 6$ second) was used for all images.

\section{Accession numbers and gene names}

The gene names given for GLEAN genes are summarized in Additional data file 7.

\section{GenBank accession numbers}

Dm-Ago3 [GenBank:EF688531], Tc-snp [GenBank:EF688530], Tc-silA [GenBank:EF688527], Tc-silB [GenBank:EF688528], Tc-silC [GenBank:EF688529]. TcAgo-1 [GenBank:EU273915], Tc-Ago-2a [GenBank:EU273916], Tc-Ago-2b [GenBank:EU273917], Tc-Dcr1 [GenBank:EU273918], Tc-Dcr-2 [GenBank:EU273919], TcR2D2 [GenBank:EU273920], Tc-C3PO [GenBank:EU273921], tag-130 deletion lesions 
[GenBank:EF695395, EF695396], tag-130OK1073 isoforms [GenBank:EF695397, EF695398].

DNA Data Bank of Japan accession numbers

Bm-sil1 [DDBJ:AB327183], Bm-sil2 [DDBJ: sil3 [DDBJ:AB327184].

\begin{abstract}
Abbreviations
dsRBM, dsRNA binding motif; dsRNA, double-stranded RNA; EGFP, enhanced green fluorescence protein; miRNA, micro-RNA; miRNP, micro-RNA ribonucleoparticle; RdRP, RNA-dependent RNA polymerase; RISC, RITS, RNAinduced initiation of transcriptional gene silencing; RNAinduced silencing complex; RNAi, RNA interference; siRNA, short interfering RNA.
\end{abstract}

\section{Authors' contributions}

YT and GB conceived and designed the experiments. GB and DG performed the annotations of the Dicer, Argonaute, and RdRP proteins. YT and SCM performed annotations of Dicer, dsRBM, Eri-1, Sid-1-related proteins, and candidate factors for systemic RNAi. YT performed the Drosophila gene cloning (Dm-Ago-3) and C. elegans experiments. YT and SCM performed Tribolium gene cloning and RNAi experiments. ST cloned the sid-1-like genes of Bombyx. MS contributed the initial annotation of sid-1-related genes. YT, SCM, and GB wrote the paper. All authors discussed the results and commented on the manuscript.

\section{Additional data files}

The following additional data are available with the online version of this paper. Additional data file 1 contains multiple alignments used for pylogenetic analyses. Additional data file 2 is a phylogenetic tree for Eri-1-like nucleases including $C$. elegans Crn-4. Additional data file 3 is sil gene expression profile in Tribolium. Additional data file 4 is a multiple alignment of full-length Sil proteins. Additional data file 5 contains Dot-matcher alignments of Sil proteins. Additional data file 6 shows C. elegans tag-13o locus and deletions. Additional data file 7 is a list of GLEAN gene number and corresponding gene names. Additional data file 8 is a table showing RNAi and miRNA components in Tribolium, Drosophila and C. elegans. Additional data file 9 is a table showing primers used for dsRNA synthesis.

\section{Acknowledgements}

We thank the Caenorhabditis Genetic Center, K Morita, M Han, A Fire, and $C$ Hunter for $C$. elegans and unc-22 E. coli strains, $H$ Robertson for help with the initial annotation of sid- $I$-like genes. YT and SCM thank C Coleman for technical assistance, E Huarcaya-Najarro, J Coolon, and M Herman for help with $C$. elegans handling, $T$ Shippy for discussion and critical reading, $M$ Jindra for discussion, $M$ Gorman and R Futahashi for discussion of systemic RNAi in mosquitos and Bombyx, respectively, and S Brown, R Denell and all of their lab members for helpful discussion and comments. TS thanks $\mathrm{K}$ Mita for providing the Bombyx cDNA library. GB and DG thank E Bucoir for help with annotation of predicted Tribolium genes. YT and SCM thank the Terry C Johnson Center for Basic Cancer Research at Kansas State University for the research equipment. This work was supported by the National Science Foundation, the National Institutes of Health, the Japanese Society for the Promotion of Science (YT), and the Deutsche Forschungsgemeinschaft (GB).

\section{References}

I. Fire A, Xu S, Montgomery MK, Kostas SA, Driver SE, Mello CC: Potent and specific genetic interference by double-stranded RNA in Caenorhabditis elegans. Nature 1998, 391:806-8II.

2. Meister G, Tuschl T: Mechanisms of gene silencing by doublestranded RNA. Nature 2004, 43 I:343-349.

3. Mello CC, Conte D Jr: Revealing the world of RNA interference. Nature 2004, 43 I:338-342.

4. Hammond SM: Dicing and slicing: the core machinery of the RNA interference pathway. FEBS Lett 2005, 579:5822-5829.

5. Dykxhoorn DM, Novina CD, Sharp PA: Killing the messenger: short RNAs that silence gene expression. Nat Rev Mol Cell Biol 2003, 4:457-467.

6. Pasquinelli $A E$, Hunter $S$, Bracht J: MicroRNAs: a developing story. Curr Opin Genet Dev 2005, 15:200-205.

7. Carmell MA, Hannon GJ: RNase III enzymes and the initiation of gene silencing. Nat Struct Mol Biol 2004, I I:2 | 4-2 I8.

8. Filipowicz W: RNAi: the nuts and bolts of the RISC machine. Cell 2005, I 22: 17-20.

9. Tabara H, Yigit E, Siomi H, Mello CC: The dsRNA binding protein RDE-4 interacts with RDE-I, DCR-I, and a DExH-box helicase to direct RNAi in C. elegans. Cell 2002, 109:86I-87I.

10. Forstemann K, Tomari Y, Du T, Vagin VV, Denli AM, Bratu DP, Klattenhoff $C$, Theurkauf WE, Zamore PD: Normal microRNA maturation and germ-line stem cell maintenance requires Loquacious, a double-stranded RNA-binding domain protein. PLoS Biol 2005, 3:e236.

II. Leuschner PJ, Obernosterer G, Martinez J: MicroRNAs: Loquacious speaks out. Curr Biol 2005, I 5:R603-605.

12. Liu Q, Rand TA, Kalidas S, Du F, Kim HE, Smith DP, Wang X: R2D2, a bridge between the initiation and effector steps of the Drosophila RNAi pathway. Science 2003, 301:192I-1925.

13. Pellino JL, Sontheimer EJ: R2D2 leads the silencing trigger to mRNA's death star. Cell 2003, I I5: | 132-133.

14. Saito K, Ishizuka A, Siomi H, Siomi MC: Processing of pre-microRNAs by the Dicer-I-Loquacious complex in Drosophila cells. PLoS Biol 2005, 3:e235.

15. Carmell MA, Xuan Z, Zhang MQ, Hannon GJ: The Argonaute family: tentacles that reach into RNAi, developmental control, stem cell maintenance, and tumorigenesis. Genes Dev 2002, 16:2733-2742.

16. Parker JS, Barford D: Argonaute: A scaffold for the function of short regulatory RNAs. Trends Biochem Sci 2006, 3 I:622-630.

17. Lee YS, Nakahara K, Pham JW, Kim K, He Z, Sontheimer EJ, Carthew RW: Distinct roles for Drosophila Dicer-I and Dicer-2 in the siRNA/miRNA silencing pathways. Cell 2004, I I 7:69-8I.

18. Okamura K, Ishizuka A, Siomi H, Siomi MC: Distinct roles for Argonaute proteins in small RNA-directed RNA cleavage pathways. Genes Dev 2004, 18:1655-1666.

19. Sijen T, Fleenor J, Simmer F, Thijssen KL, Parrish S, Timmons L, Plasterk $\mathrm{RH}$, Fire A: On the role of RNA amplification in dsRNAtriggered gene silencing. Cell 200I, 107:465-476.

20. Smardon A, Spoerke JM, Stacey SC, Klein ME, Mackin N, Maine EM: EGO-I is related to RNA-directed RNA polymerase and functions in germ-line development and RNA interference in C. elegans. Curr Biol 2000, 10:169-178.

21. Sijen T, Steiner FA, Thijssen KL, Plasterk RH: Secondary siRNAs result from unprimed RNA synthesis and form a distinct class. Science 2007, 3 1 5:244-247.

22. Kennerdell JR, Carthew RW: Use of dsRNA-mediated genetic interference to demonstrate that frizzled and frizzled 2 act in the wingless pathway. Cell 1998, 95:1017-1026.

23. Fortier E, Belote JM: Temperature-dependent gene silencing by an expressed inverted repeat in Drosophila. Genesis 2000, 26:240-244.

24. Kennerdell JR, Carthew RW: Heritable gene silencing in Drosophila using double-stranded RNA. Nat Biotechnol 2000, 


\section{8:896-898.}

25. Piccin A, Salameh A, Benna C, Sandrelli F, Mazzotta G, Zordan M, Rosato E, Kyriacou CP, Costa R: Efficient and heritable functional knock-out of an adult phenotype in Drosophila using a GAL4-driven hairpin RNA incorporating a heterologous spacer. Nucleic Acids Res 200I, 29:E55.

26. Uhlirova M, Foy BD, Beaty BJ, Olson KE, Riddiford LM, Jindra M: Use of Sindbis virus-mediated RNA interference to demonstrate a conserved role of Broad-Complex in insect metamorphosis. Proc Natl Acad Sci USA 2003, I 00: I5607-I56 I2.

27. Tomoyasu Y, Denell RE: Larval RNAi in Tribolium (Coleoptera) for analyzing adult development. Dev Genes Evol 2004, 2 | 4:575-578.

28. Dong Y, Friedrich M: Nymphal RNAi: systemic RNAi mediated gene knockdown in juvenile grasshopper. BMC Biotechnol 2005, 5:25

29. Erezyilmaz DF, Riddiford LM, Truman JW: The pupal specifier broad directs progressive morphogenesis in a direct-developing insect. Proc Natl Acad Sci USA 2006, I 03:6925-6930.

30. Nishikawa T, Natori S: Targeted disruption of a pupal hemocyte protein of Sarcophaga by RNA interference. Eur J Biochem 2001, 268:5295-5299.

31. Kuwayama H, Yaginuma T, Yamashita O, Niimi T: Germ-line transformation and RNAi of the ladybird beetle, Harmonia axyridis. Insect Mol Biol 2006, I 5:507-5 I 2 .

32. Amdam GV, Simoes ZL, Guidugli KR, Norberg K, Omholt SW: Disruption of vitellogenin gene function in adult honeybees by intra-abdominal injection of double-stranded RNA. BMC Biotechnol 2003, 3:I.

33. Blandin S, Moita LF, Kocher T, Wilm M, Kafatos FC, Levashina EA: Reverse genetics in the mosquito Anopheles gambiae : targeted disruption of the Defensin gene. EMBO Rep 2002, 3:852-856

34. Boisson B, Jacques JC, Choumet V, Martin E, Xu J, Vernick K, Bourgouin $C$ : Gene silencing in mosquito salivary glands by RNAi. FEBS Lett 2006, 580:1988-1992.

35. Dzitoyeva S, Dimitrijevic N, Manev H: Intra-abdominal injection of double-stranded RNA into anesthetized adult Drosophila triggers RNA interference in the central nervous system. Mol Psychiatry 200I, 6:665-670.

36. Goto A, Blandin S, Royet J, Reichhart JM, Levashina EA: Silencing of Toll pathway components by direct injection of doublestranded RNA into Drosophila adult flies. Nucleic Acids Res 2003, 31:6619-6623

37. Zhu J, Chen L, Raikhel AS: Posttranscriptional control of the competence factor betaFTZ-FI by juvenile hormone in the mosquito Aedes aegypti. Proc Natl Acad Sci USA 2003, 100:13338-13343.

38. Patel A, Fondrk MK, Kaftanoglu O, Emore C, Hunt G, Frederick K, Amdam GV: The making of a queen: TOR pathway is a key player in diphenic caste development. PLOS ONE 2007, 2:e509.

39. Turner CT, Davy MW, MacDiarmid RM, Plummer KM, Birch NP, Newcomb RD: RNA interference in the light brown apple moth, Epiphyas postvittana (Walker) induced by doublestranded RNA feeding. Insect Mol Biol 2006, I 5:383-39I.

40. Sanchez Alvarado A, Newmark PA: Double-stranded RNA specifically disrupts gene expression during planarian regeneration. Proc Natl Acad Sci USA 1999, 96:5049-5054.

4I. Bucher G, Scholten J, Klingler M: Parental RNAi in Tribolium (Coleoptera). Curr Biol 2002, I 2:R85-86.

42. Lynch JA, Desplan C: A method for parental RNA interference in the wasp Nasonia vitripennis. Nat Protoc 2006, I:486-494.

43. Mito T, Sarashina I, Zhang H, Iwahashi A, Okamoto H, Miyawaki K, Shinmyo $Y$, Ohuchi $\mathrm{H}$, Noji S: Non-canonical functions of hunchback in segment patterning of the intermediate germ cricket Gryllus bimaculatus. Development 2005, I 32:2069-2079.

44. Liu PZ, Kaufman TC: hunchback is required for suppression of abdominal identity, and for proper germband growth and segmentation in the intermediate germband insect Oncopeltus fasciatus. Development 2004, I3 |:|5 |5-1527.

45. Dzitoyeva S, Dimitrijevic N, Manev H: Identification of a novel Drosophila gene, beltless, using injectable embryonic and adult RNA interference (RNAi). BMC Genomics 2003, 4:33.

46. Marcus JM: Jumping genes and AFLP maps: transforming lepidopteran color pattern genetics. Evol Dev 2005, 7:108-1 |4.

47. Huang J, Zhang Y, Li M, Wang S, Liu W, Couble P, Zhao G, Huang Y: RNA interference-mediated silencing of the bursicon gene induces defects in wing expansion of silkworm. FEBS Lett 2007 ,
$581: 697-701$.

48. Ohnishi A, Hull JJ, Matsumoto S: Targeted disruption of genes in the Bombyx mori sex pheromone biosynthetic pathway. Proc Natl Acad Sci USA 2006, I 03:4398-4403.

49. Tabunoki H, Higurashi S, Ninagi O, Fujii H, Banno Y, Nozaki M, Kitajima M, Miura N, Atsumi S, Tsuchida K, Maekawa H, Sato R: A carotenoid-binding protein (CBP) plays a crucial role in cocoon pigmentation of silkworm (Bombyx mori) larvae. FEBS Lett 2004, 567: 175-178.

50. Palauqui JC, Elmayan T, Pollien JM, Vaucheret $\mathrm{H}$ : Systemic acquired silencing: transgene-specific post-transcriptional silencing is transmitted by grafting from silenced stocks to non-silenced scions. EMBO J 1997, I 6:4738-4745.

51. Voinnet $O$, Baulcombe DC: Systemic signalling in gene silencing. Nature 1997, 389:553.

52. Voinnet O, Vain P, Angell S, Baulcombe DC: Systemic spread of sequence-specific transgene RNA degradation in plants is initiated by localized introduction of ectopic promoterless DNA. Cell 1998, 95:177-187.

53. Winston WM, Molodowitch C, Hunter CP: Systemic RNAi in C. elegans requires the putative transmembrane protein SID-I. Science 2002, 295:2456-2459.

54. Xie Q, Guo HS: Systemic antiviral silencing in plants. Virus Res 2006, I I 8: I-6.

55. Voinnet O: Non-cell autonomous RNA silencing. FEBS Lett 2005, 579:5858-587।

56. Mlotshwa S, Voinnet O, Mette MF, Matzke M, Vaucheret H, Ding SW, Pruss G, Vance VB: RNA silencing and the mobile silencing signal. Plant Cell 2002, I 4(Suppl):S289-30I.

57. May RC, Plasterk RH: RNA interference spreading in C. elegans. Methods Enzymol 2005, 392:308-3I5.

58. Timmons L, Tabara H, Mello CC, Fire AZ: Inducible systemic RNA silencing in Caenorhabditis elegans. Mol Biol Cell 2003, | 4:2972-2983.

59. Feinberg $\mathrm{EH}$, Hunter CP: Transport of dsRNA into cells by the transmembrane protein SID-I. Science 2003, 30 I: I 545-I547.

60. Tijsterman M, May RC, Simmer F, Okihara KL, Plasterk RH: Genes required for systemic RNA interference in Caenorhabditis elegans. Curr Biol 2004, I 4: I I I- I I6.

6I. Ulvila J, Parikka M, Kleino A, Sormunen R, Ezekowitz RA, Kocks C, Ramet $M$ : Double-stranded RNA is internalized by scavenger receptor-mediated endocytosis in Drosophila S2 cells. J Biol Chem 2006, 28 I : |4370-|4375.

62. Saleh MC, van Rij RP, Hekele A, Gillis A, Foley E, O'Farrell PH, Andino $R$ : The endocytic pathway mediates cell entry of dsRNA to induce RNAi silencing. Nat Cell Biol 2006, 8:793-802.

63. Tabara H, Sarkissian M, Kelly WG, Fleenor J, Grishok A, Timmons L, Fire A, Mello CC: The rde-I gene, RNA interference, and transposon silencing in C. elegans. Cell I999, 99: I23-132.

64. Parrish S, Fire A: Distinct roles for RDE-I and RDE-4 during RNA interference in Caenorhabditis elegans. Rna 2001, 7:|397-|402

65. Roignant JY, Carre C, Mugat B, Szymczak D, Lepesant JA, Antoniewski $C$ : Absence of transitive and systemic pathways allows cell-specific and isoform-specific RNAi in Drosophila. Rna 2003, 9:299-308.

66. Tribolium Genome Sequencing Consortium: The genome of the developmental model beetle and pest Tribolium castaneum. Nature 2008 in press.

67. Bernstein E, Caudy AA, Hammond SM, Hannon GJ: Role for a bidentate ribonuclease in the initiation step of RNA interference. Nature 200I, 409:363-366.

68. Knight SW, Bass BL: A role for the RNase III enzyme DCR-I in RNA interference and germ line development in Caenorhabditis elegans. Science 200I, 293:2269-227I.

69. Ketting RF, Fischer SE, Bernstein E, Sijen T, Hannon GJ, Plasterk RH: Dicer functions in RNA interference and in synthesis of small RNA involved in developmental timing in C. elegans. Genes Dev 200I, I 5:2654-2659.

70. Lee Y, Ahn C, Han J, Choi H, Kim J, Yim J, Lee J, Provost P, Radmark $\mathrm{O}, \mathrm{Kim}$ S, Kim VN: The nuclear RNase III Drosha initiates microRNA processing. Nature 2003, 425:415-4I9.

7I. Filippov V, Solovyev V, Filippova M, Gill SS: A novel type of RNase III family proteins in eukaryotes. Gene 2000, 245:2 I3-22I.

72. de Castro E, Sigrist C], Gattiker A, Bulliard V, Langendijk-Genevaux PS, Gasteiger E, Bairoch A, Hulo N: ScanProsite: detection of PROSITE signature matches and ProRule-associated functional and structural residues in proteins. Nucleic Acids Res 
2006, 34:W362-365.

73. Denli AM, Tops BB, Plasterk RH, Ketting RF, Hannon GJ: Processing of primary microRNAs by the Microprocessor complex. Nature 2004, 432:23I-235.

74. Lippman Z, Martienssen R: The role of RNA interference in heterochromatic silencing. Nature 2004, 43 I :364-370.

75. Verdel A, Jia S, Gerber S, Sugiyama T, Gygi S, Grewal SI, Moazed D: RNAi-mediated targeting of heterochromatin by the RITS complex. Science 2004, 303:672-676.

76. Pal-Bhadra M, Leibovitch BA, Gandhi SG, Rao M, Bhadra U, Birchler JA, Elgin SC: Heterochromatic silencing and HPI localization in Drosophila are dependent on the RNAi machinery. Science 2004, 303:669-672.

77. Brennecke J, Aravin AA, Stark A, Dus M, Kellis M, Sachidanandam R, Hannon G]: Discrete small RNA-generating loci as master regulators of transposon activity in Drosophila. Cell 2007, 128:1089-1103.

78. Lin H: piRNAs in the germ line. Science 2007, 3 | 6:397.

79. O'Donnell KA, Boeke JD: Mighty Piwis defend the germline against genome intruders. Cell 2007, I 29:37-44

80. Yigit E, Batista PJ, Bei Y, Pang KM, Chen CC, Tolia NH, Joshua-Tor L, Mitani S, Simard MJ, Mello CC: Analysis of the C. elegans Argonaute family reveals that distinct Argonautes act sequentially during RNAi. Cell 2006, I 27:747-757.

8I. Grishok A, Pasquinelli AE, Conte D, Li N, Parrish S, Ha I, Baillie DL, Fire A, Ruvkun G, Mello CC: Genes and mechanisms related to RNA interference regulate expression of the small temporal RNAs that control C. elegans developmental timing. Cell 200I, I 06:23-34.

82. Gunawardane LS, Saito K, Nishida KM, Miyoshi K, Kawamura Y, Nagami T, Siomi H, Siomi MC: A slicer-mediated mechanism for repeat-associated siRNA 5' end formation in Drosophila. Science 2007, 3 I 5: I587-I590.

83. Parrish S, Fleenor J, Xu S, Mello C, Fire A: Functional anatomy of a dsRNA trigger: differential requirement for the two trigger strands in RNA interference. Mol Cell 2000, 6:1077-1087.

84. Dalmay T, Hamilton A, Rudd S, Angell S, Baulcombe DC: An RNAdependent RNA polymerase gene in Arabidopsis is required for posttranscriptional gene silencing mediated by a transgene but not by a virus. Cell 2000, I 0I:543-553.

85. Mourrain P, Béclin C, Elmayan T, Feuerbach F, Godon C, Morel JB, Jouette D, Lacombe AM, Nikic S, Picault N, Rémoué K, Sanial M, Vo TA, Vaucheret H: Arabidopsis SGS2 and SGS3 genes are required for posttranscriptional gene silencing and natural virus resistance. Cell 2000, I 0 I:533-542.

86. Vienne A, Shiina T, Abi-Rached L, Danchin E, Vitiello V, Cartault F, Inoko H, Pontarotti P: Evolution of the proto-MHC ancestral region: more evidence for the plesiomorphic organisation of human chromosome 9q34 region. Immunogenetics 2003, 55:429-436.

87. Kennedy S, Wang D, Ruvkun G: A conserved siRNA-degrading RNase negatively regulates RNA interference in C. elegans. Nature 2004, 427:645-649.

88. Dominski Z, Yang XC, Kaygun H, Dadlez M, Marzluff WF: A 3' exonuclease that specifically interacts with the $3^{\prime}$ end of histone mRNA. Mol Cell 2003, I 2:295-305.

89. Spielhaupter C, Schatzl HM: PrPC directly interacts with proteins involved in signaling pathways. J Biol Chem 200I, 276:44604-44612

90. Kupsco JM, Wu MJ, Marzluff WF, Thapar R, Duronio RJ: Genetic and biochemical characterization of Drosophila Snipper: a promiscuous member of the metazoan 3'hExo/ERI-I family of 3' to 5' exonucleases. Rna 2006, I 2:2103-2II7.

91. Parrish JZ, Xue D: Functional genomic analysis of apoptotic DNA degradation in C. elegans. Mol Cell 2003, I I:987-996.

92. Duxbury MS, Ashley SW, Whang EE: RNA interference: a mammalian SID-I homologue enhances siRNA uptake and gene silencing efficacy in human cells. Biochem Biophys Res Commun 2005, $331: 459-463$.

93. Honeybee Genome Sequencing Consortium: Insights into social insects from the genome of the honeybee Apis mellifera. Nature 2006, 443:931-949.

94. Aronstein K, Pankiw T, Saldivar E: Sid-I is implicated in systemic gene silencing in the honey bee. J Apicultural Res 2006, 45:20-24.

95. Moerman DG, Benian GM, Waterston RH: Molecular cloning of the muscle gene unc-22 in Caenorhabditis elegans by $\mathrm{Tcl}$ transposon tagging. Proc Natl Acad Sci USA 1986, 83:2579-2583.

96. Overstreet E, Chen X, Wendland B, Fischer JA: Either part of a
Drosophila epsin protein, divided after the ENTH domain, functions in endocytosis of delta in the developing eye. Curr Biol 2003, I3:854-860.

97. Overstreet E, Fitch E, Fischer JA: Fat facets and Liquid facets promote Delta endocytosis and Delta signaling in the signaling cells. Development 2004, I 3 I:5355-5366

98. Wang W, Struhl G: Drosophila Epsin mediates a select endocytic pathway that DSL ligands must enter to activate Notch. Development 2004, I 3 I:5367-5380.

99. Peiser L, Mukhopadhyay S, Gordon S: Scavenger receptors in innate immunity. Curr Opin Immunol 2002, I 4: I23-I28.

100. Ramet M, Pearson A, Manfruelli P, Li X, Koziel H, Gobel V, Chung E, Krieger M, Ezekowitz RA: Drosophila scavenger receptor $\mathrm{Cl}$ is a pattern recognition receptor for bacteria. Immunity 200I, I 5: | 027-1038.

I0I. Kurucz E, Markus R, Zsamboki J, Folkl-Medzihradszky K, Darula Z, Vilmos P, Udvardy A, Krausz I, Lukacsovich T, Gateff E: Nimrod, a putative phagocytosis receptor with EGF repeats in Drosophila plasmatocytes. Curr Biol 2007, I 7:649-654.

102. Kocks C, Cho JH, Nehme N, Ulvila J, Pearson AM, Meister M, Strom C, Conto SL, Hetru C, Stuart LM, Stehle T, Hoffmann JA, Reichhart $J M$, Ferrandon D, Rämet M, Ezekowitz RA: Eater, a transmembrane protein mediating phagocytosis of bacterial pathogens in Drosophila. Cell 2005, I 23:335-346.

103. Tomoyasu $Y$, Wheeler SR, Denell RE: Ultrabithorax is required for membranous wing identity in the beetle Tribolium castaneum. Nature 2005, 433:643-647.

104. Kortschak RD, Samuel G, Saint R, Miller DJ: EST analysis of the cnidarian Acropora millepora reveals extensive gene loss and rapid sequence divergence in the model invertebrates. Curr Biol 2003, I 3:2190-2195.

105. Dzitoyeva S, Dimitrijevic N, Manev H: Gamma-aminobutyric acid $B$ receptor I mediates behavior-impairing actions of alcohol in Drosophila. Proc Natl Acad Sci USA 2003, 1 00:5485-5490.

106. Petruk S, Sedkov Y, Riley KM, Hodgson J, Schweisguth F, Hirose S, Jaynes JB, Brock HW, Mazo A: Transcription of bxd noncoding RNAs promoted by trithorax represses Ubx in cis by transcriptional interference. Cell 2006, I 27:I209-I22I.

107. Zawadzki JL, Presidente PJ, Meeusen EN, De Veer MJ: RNAi in Haemonchus contortus : a potential method for target validation. Trends Parasitol 2006, 22:495-499.

108. Arakane Y, Muthukrishnan S, Kramer KJ, Specht CA, Tomoyasu Y, Lorenzen MD, Kanost M, Beeman RW: The Tribolium chitin synthase genes TcCHSI and TcCHS2 are specialized for synthesis of epidermal cuticle and midgut peritrophic matrix. Insect Mol Biol 2005, I 4:453-463.

109. Leaman D, Chen PY, Fak J, Yalcin A, Pearce M, Unnerstall U, Marks DS, Sander C, Tuschl T, Gaul U: Antisense-mediated depletion reveals essential and specific functions of microRNAs in Drosophila development. Cell 2005, I 2 I : I097-I I 08.

I I0. Tijsterman $M$, Ketting RF, Plasterk RH: The genetics of RNA silencing. Annu Rev Genet 2002, 36:489-519.

III. Ullu E, Tschudi C, Chakraborty T: RNA interference in protozoan parasites. Cell Microbiol 2004, 6:509-5I9.

112. Pavlopoulos A, Berghammer AJ, Averof M, Klingler M: Efficient transformation of the beetle Tribolium castaneum using the Minos transposable element: quantitative and qualitative analysis of genomic integration events. Genetics 2004, 1 67:737-746.

I 13. Lorenzen MD, Kimzey T, Shippy TD, Brown SJ, Denell RE, Beeman RW: piggyBac-based insertional mutagenesis in Tribolium castaneum using donor/helper hybrids. Insect Mol Biol 2007, 1 6:265-275

I14. Lorenzen MD, Berghammer AJ, Brown SJ, Denell RE, Klingler M, Beeman RW: piggyBac-mediated germline transformation in the beetle Tribolium castaneum. Insect Mol Biol 2003, I 2:433-440.

I I5. Berghammer AJ, Klingler M, Wimmer EA: A universal marker for transgenic insects. Nature 1999, 402:370-37I.

I 16. Beeman RW, Brown S]: RAPD-based genetic linkage maps of Tribolium castaneum. Genetics 1999, I 53:333-338.

I17. Beeman RW, Johnson TR, Nanis SM: Chromosome rearrangements in Tribolium. J Heredity 1986, 77:45 I-456.

118. Klingler M: Tribolium. Curr Biol 2004, I 4:R639-640.

119. Mocelin G, Stuart J]: Crossover suppressors in Tribolium castaneum. J Heredity 1996, 87:27-34.

120. BeetleBase [http://www.bioinformatics.ksu.edu/]

121. Tribolium castaneum Genome Project Website [http:// www.hgsc.bcm.tmc.edu/projects/tribolium/] 
122. Dotmatcher [http://srs.ebi.ac.uk/srsbin/cgi-biwgetzpage+Launch+id+3dfFAIUTLh0+-appl+dotmatcherP+-launch From+top]

123. Kumar S, Tamura K, Nei M: MEGA3: Integrated software for Molecular Evolutionary Genetics Analysis and sequence alignment. Brief Bioinform 2004, 5:150-163.

124. TreePuzzle for Maximum Likelihood Analysis [http://bio web.pasteur.fr/seqanal/interfaces/Puzzle.html]

125. TreeView [http://taxonomy.zoology.gla.ac.uk/rod/treeview.html]

126. Nematode.net [http://www.nematode.net]

127. ScanProsite [http://us.expasy.org/prosite/]

128. PROSITE User Manual [http://www.expasy.org/prosite/pro suser.html]

129. TMHMM Server v. 2.0 [http://www.cbs.dtu.dk/services/TMHMM/ ]

130. InterProScan [http://www.ebi.ac.uk/InterProScan/]

|31. KAIKObase [http://sgp.dna.affrc.go.jp/index.html]

132. Mita K, Morimyo M, Okano K, Koike Y, Nohata J, Kawasaki H, Kadono-Okuda K, Yamamoto K, Suzuki MG, Shimada T, Goldsmith MR, Maeda S: The construction of an EST database for Bombyx mori and its application. Proc Natl Acad Sci USA 2003, 100: $|4| 2|-| 4 \mid 26$.

133. Kamath RS, Martinez-Campos M, Zipperlen P, Fraser AG, Ahringer J: Effectiveness of specific RNA-mediated interference through ingested double-stranded RNA in Caenorhabditis elegans. Genome Biol 200I, 2:RESEARCH0002.

134. Gloor GB, Preston CR, Johnson-Schlitz DM, Nassif NA, Phillis RW, Benz WK, Robertson HM, Engels WR: Type I repressors of $\mathbf{P}$ element mobility. Genetics 1993, I35:81-95.

135. Lee Y, Hur I, Park SY, Kim YK, Suh MR, Kim VN: The role of PACT in the RNA silencing pathway. EMBO J 2006, 25:522-532.

136. Chendrimada TP, Gregory RI, Kumaraswamy E, Norman J, Cooch N, Nishikura K, Shiekhattar R: TRBP recruits the Dicer complex to Ago2 for microRNA processing and gene silencing. Nature 2005, 436:740-744.

137. Haase AD, Jaskiewicz L, Zhang H, Laine S, Sack R, Gatignol A, Filipowicz W: TRBP, a regulator of cellular PKR and HIV-I virus expression, interacts with Dicer and functions in RNA silencing. EMBO Rep 2005, 6:96I-967.

138. Gregory RI, Yan KP, Amuthan G, Chendrimada T, Doratotaj B, Cooch N, Shiekhattar R: The Microprocessor complex mediates the genesis of microRNAs. Nature 2004, 432:235-240. 